\title{
Tail colour signals performance in blue tit nestlings
}

\section{Class, Barbara}

2019-09

Class , B , Kluen , E \& Brommer , J E 2019 , ' Tail colour signals performance in blue tit nestlings ' , Journal of Evolutionary Biology , vol. 32 , no. 9 , pp. 913-920 . https://doi.org/10.1111/jeb.13489

http://hdl.handle.net/10138/327128

https://doi.org/10.1111/jeb.13489

acceptedVersion

Downloaded from Helda, University of Helsinki institutional repository.

This is an electronic reprint of the original article.

This reprint may differ from the original in pagination and typographic detail.

Please cite the original version. 


\section{JOURNAL OF Evolutionary Biology ,}

Tail color signals performance in blue tit nestlings

\begin{tabular}{|r|l|}
\hline Journal: & Journal of Evolutionary Biology \\
\hline Manuscript ID & JEB-2018-00555.R3 \\
\hline Manuscript Type: & Research Papers \\
\hline Keywords: & $\begin{array}{l}\text { Sexual selection, Coloration, Good genes, G matrix, Heritability, } \\
\text { Cyanistes caeruleus, Wild, Immune response }\end{array}$ \\
\hline \multicolumn{2}{|l}{} \\
\hline
\end{tabular}




\section{Abstract}

4 Indirect sexual selection arises when reproductive individuals choose their mates based on

5 heritable ornaments that are genetically correlated to fitness. Evidence for genetic associations between ornamental coloration and fitness remain scarce. In this study we investigate the

7 quantitative genetic relationship between different aspects of tail structural coloration 8 (brightness, hue and UV chroma) and performance (cell mediated immunity, body mass and 9 wing length) in blue tit (Cyanistes caeruleus) nestlings. In line with previous studies, we find low heritability for structural coloration and moderate heritability for performance measures. Multivariate animal models show positive genetic correlations between the three measures of performance, indicating quantitative genetic variation for overall performance while tail brightness and UV chroma, two genetically independent color measures, are genetically correlated with performance (positively and negatively respectively). Our results suggest that mate choice based on independent aspects of tail coloration can have fitness payoffs in blue tits and provide support for the indirect benefits hypothesis. However, low heritability of tail structural coloration implies that indirect sexual selection on mate choice for this ornament will be a weak evolutionary force.

Keywords: Sexual selection, coloration, good genes, genetic correlation, G matrix, heritability, Cyanistes caeruleus, wild, immune response 


\section{Introduction}

Sexual selection theory has provided a powerful framework to understand the existence and function of ornaments. Reproductive individuals are predicted to choose their mates based on potential direct benefits ("good parent") or indirect benefits ("good genes") that they provide (Kirkpatrick \& Barton 1997). In particular, the good genes model implies that genes increasing fitness can be phenotypically signaled by individuals, for example through ornamentation. While direct benefits models of mate choice have been well supported empirically, the indirect benefits models requires that ornaments and fitness are heritable and positively genetically correlated (Kirkpatrick \& Barton 1997), which thus far is lacking evidence (Jones \& Ratterman 2009).

Birds often exhibit colorful plumage patches, which have been extensively studied in relation to mate choice and intra-sexual competition (Amundsen 2000). In particular, box-breeding birds are ideal study systems to test for indirect benefits of ornaments because they allow longterm monitoring and cross-fostering experiment. Indeed, the combination of pedigree data obtained through long-term monitoring, and cross-fostering can be effectively used to decompose environmental from genetic resemblance between relatives (Kruuk \& Hadfield 2007). Cross-fostering experiments are used to separately estimate the effects of foster and genetic parents' traits on offspring performance (e.g. growth, mass, immunity) or viability, the former capturing direct effects (through parental care) and the latter capturing indirect (genetic) effects (assuming the absence of early environmental and maternal effects). In great tits (Parus major) for example, such experiments have provided support for direct and indirect benefits of carotenoid and melanin-based coloration in males and females. Indeed, great tits with a larger black breast stripe were found to produce more viable or heavier young (Norris 1993, Remeš \& Matysiokova 2013) while yellower males and females with a blacker breast stripe were found to raise heavier nestlings (Pickett et al. 2013). 
In combination with cross-fostering, quantitative genetics, which use information on the relatedness between individuals derived from the population pedigree, are particularly relevant to study sexual selection (Reid 2014). Indeed, this approach allows disentangling early environmental or maternal effects from additive genetic effects causing resemblance between relatives (Kruuk \& Hadfield 2007), which cannot be done using only cross-fostering. In practice, a (co)variance partitioning approach implemented using (multivariate) mixed models, can be used to estimate the heritability of ornaments, fitness and their genetic correlation along with other sources of variance in and covariance between them (e.g. year, mother, nest of rearing). Earlier quantitative genetic studies find low heritability for structural and carotenoidbased ornaments (Hadfield et al. 2006, Evans \& Sheldon 2012, Drobniak et al. 2013, Charmantier et al. 2017), as well as recruitment (Hadfield et al. 2006) in blue tits (Cyanistes caeruleus). In contrast, performance traits which are correlates of fitness, such as body condition or growth in nestlings, are found to be moderately heritable in collared flycatchers (Ficedula albicollis, Merilä et al. 2001, Pitala et al. 2007) and blue tits (Hadfield et al. 2007). To our knowledge, only two studies estimated the genetic correlation between a structural color ornament and fitness, and did not find support for the indirect benefits hypothesis (Hadfield et al. 2006, Qvarnström et al. 2006).

Under a particular case of the indirect benefits hypothesis, the "parasite-mediated sexual selection" (PMSS) hypothesis (cf. Hamilton \& Zuk 1982), individuals' sexual ornaments are predicted to signal immunocompetence. This hypothesis is based on the idea that cycles of coadaptation between hosts and parasites, which maintain additive genetic variation in resistance and thus fitness in hosts, can promote sexual selection for displays that signal resistance. Within species exposed to various chronic parasites, showiness is hence predicted to signal resistance to a wide variety of parasites. One common proxy of immunocompetence is the T-cell mediated immune response, assayed using phytohaemagglutinin (PHA). Although 
PHA was shown to be condition-dependent (Alonso-Alvarez \& Tella 2001, Thompson et al. 2014), several studies showed that it is heritable in various bird populations and species (Pitala et al. 2007, Bonneaud et al. 2009, Kinnard \& Westneat 2009, Kim et al. 2013, Sakaluk et al. 2014). To date, the few cross-fostering studies testing the association between males' or females' ornaments and nestlings' PHA find mixed evidence for the presence of such relationship. In the blue-footed booby (Sula nebouxii), Velando et al. (2005) found no correlation between nestling PHA and father's foot coloration while in great tits, Pickett at al. (2013) found a positive correlation between nestlings' PHA and genetic father's but not mother's yellow plumage brightness. In the same species, Remeš \& Matysiokova (2013) found that females with more immaculate white cheeks produce offspring with a higher PHA. In addition, only two studies estimated genetic correlations between coloration and PHA in adult male zebra finches (Taeniopygia guttata, Birkhead et al. 2006) and in common kestrel nestlings (Falco tinnunculus, Kim et al. 2013) and did not support the PMSS hypothesis.

Therefore, empirical evidence for the indirect fitness benefits and PMSS hypotheses remains equivocal, and more quantitative genetic studies are needed to gain insights into the evolution of color ornaments through sexual selection. In the present study, we investigate the quantitative genetic association between blue ornamentation and performance in blue tit nestlings. In this species, structural colors, in particular the blue cap of adults, have been extensively studied. This ornament has been shown to be sexually dimorphic (Hunt et al. 1998) and involved in mate choice (Andersson et al. 1998, Hunt et al. 1999) and intra-sexual competition (AlonsoAlvarez et al. 2004, Remy et al. 2010). In addition to their cap, blue tits show sexually dimorphic blue coloration of their tail feathers, which is already detectable at the nestling stage (Johnsen et al. 2003). Because most birds do not molt their tail feathers during their first year (Peters et al. 2007, Svensson 1992), the structural coloration of tail feathers may be involved in sexual selection. Here, we estimate genetic correlations between different aspects of tail 
structural color (brightness, hue, UV chroma) and different performance measures (PHA, body mass, and wing length) using a multivariate animal model. This study provides rare estimates of genetic correlations between color and performance and supports the indirect benefits hypothesis.

\section{Material \& Methods}

\section{Measures of blue tit nestlings}

Blue tits were studied in a nest-box breeding population in south-west Finland (Tammisaari, $60^{0} 01^{\prime} \mathrm{N}, 23^{0} 31^{\prime} \mathrm{E}$ ). Hatch date of a brood (day 0 ) was established by daily checks. When the offspring were 2 days old (2005-2009), approximately half of each brood (on average 42 $\pm 9 \%$ ) was reciprocally swapped between a pair of nests with same aged and similar sized offspring (average brood mass at day 0 ). Nestlings were weighed and individually marked by clipping their nails. Whether the heaviest nestling was cross-fostered or not was decided at random and this action was subsequently alternated down the mass ranking of offspring (for more details see Brommer \& Kluen 2012). When nestlings were 13 days old, the thickness of their wing web after feather removal was measured (to the nearest $0.01 \mathrm{~mm}$ ) two times using a spessimetre (Mitutoya 700-117SU, modified by the removal of a spring). Nestlings were injected with 0.04 $\mathrm{ml}$ of a solution of $5 \mathrm{mg} \mathrm{ml}^{-1}$ Phytohaemagluttin (Sigma code L-8754) in saline. After 24 hours, the thickness of the wing web was measured (to the nearest $0.01 \mathrm{~mm}$ ) three times and PHA, which is the responsive swelling, was calculated as the difference between the average thickness before and after injection. This procedure was carried out from 2003 to 2007 (except in 2004). A higher PHA reflects a stronger T-cell mediated response and is a measure of innate immunity (Smits et al. 1999). When nestlings were 16 days old, their tarsus length was measured with a sliding caliper ( $0.1 \mathrm{~mm}$ accuracy) and they were weighed using a spring balance (accuracy $0.1 \mathrm{~g}$ ). 
121 Their wing length was measured using a ruler (1mm accuracy) and then one middle tail feather

122

123

124

125

126

127

128

129

130

131

132

133

134

135

136

137

138

139

140

141

142

143

144

was pulled. Nestlings were sexed using molecular markers (see Brommer \& Kluen 2012).

\section{Spectrometry}

Reflectance was measured in the lab using a spectrometer (Avantes AvaSpec-2048-SPU2) and a deuterium-halogen light source (AvaLight-DH-S). The light source and the probe were maintained at a $90^{\circ}$ angle. Reflectance of the blue in the tail feather of offspring was measured just where the feather vane comes out of the blood shaft of the feather. Because this spot is rather small in nestlings and can be missed by the incident light beam, we measured its reflectance five times. Each spectra was smoothed using a $\pm 10 \mathrm{~nm}$ running average and we discarded measurements where reflectance did not decrease between 320 and $600 \mathrm{~nm}$, which is the general pattern observed for tail structural coloration (see Johnsen et al. 2003 and Figure S1). Feathers collected in 2005 and 2006 were measured in 2006-2007 (University of Jyväskylä, spectrophotometer 1) while the rest of the feathers (2003, 2007-2009) was measured in 20092010 (University of Turku) on a different spectrometer of the same model (spectrophotometer 2). Spectra obtained from these two spectrometers have different averages (Figure S1), which was accounted for statistically in further analyses. We used reflectance values measured between 320 and $600 \mathrm{~nm}$ in the calculations of the following metrics of coloration: (1) Brightness was quantified as the total reflectance of the feather, (2) hue was calculated as the wavelength of maximum reflectance and (3) UV chroma as the proportion of the total reflectance comprised between 320 and 400nm. Sample sizes (number of individuals and broods), means and standard deviations for each trait are provided in Table 1 and their distribution is plotted in Figure S2. The length of the vane of the feather was measured using a sliding caliper and was used as a covariate in all analyses.

\section{Quantitative genetic analyses}


The pruned pedigree (including all phenotyped individuals and up to 3 generations of unphenotyped links between them) was obtained using the function trimPed from the R package "pedigree" (Coster 2012) and was analyzed using the R package "pedantics" (Morrissey 2018). It holds records for 3652 individuals, of which 671 are founders. Mean maternal and paternal sibship sizes are 10.1 and 10.5 respectively, with 2950 dams and 2709 sires. This pedigree was collected over multiple generations, with a maximum pedigree depth of 5 generations, and 2592 grandparents. All nestlings hatched in a nest were assumed to be sired by their social father. Extra-pair paternity in this population is not known but is probably within the range of what was found in other populations (7-25\%, Brommer et al. 2010). This level of extra-pair paternity is likely to cause little error in the estimation of quantitative genetic parameters (Charmantier $\&$ Réale 2005). There was phenotypic data for 430 genetic broods and on average $69 \%$ of them (65\%-89\%) were reciprocally cross-fostered each year during 2005-2009. Broods from 2003 were not cross-fostered but represent less than $5 \%$ of all broods, which is unlikely to affect our estimates of quantitative genetic (co) variances.

We first estimated additive genetic variance for tail brightness, hue, UV chroma, PHA, body mass, and wing length separately using univariate animal models. An animal model is a form of mixed model which allows partitioning phenotypic variance into variance due to additive genetic effects and other sources of variation, using information on the relatedness between individuals derived from the population pedigree (Wilson et al. 2009). This model is noted:

$$
y=X \beta+Z_{A} \boldsymbol{u}_{\boldsymbol{A}}+Z_{C E} \boldsymbol{u}_{C E}+\boldsymbol{\varepsilon}
$$

Where $\mathbf{y}$ is a vector containing all observations on all individuals for each trait, $\beta$ is a vector of fixed effects and $\mathrm{X}$ the design matrix relating fixed effects to each individual observation. The vector $\boldsymbol{u}_{A}$, fitted as a random effect, is the vector of additive genetic effects, and its covariance structure is assumed to be proportional to the relatedness matrix $Z_{A}$. To account for common 
environmental effects occurring when individuals share the same nest, $\boldsymbol{u}_{\boldsymbol{C}}$ (and its design matrix $Z_{C E}$ ) was fitted as an additional random effect. Finally, $\boldsymbol{\varepsilon}$ is a vector of residual errors capturing differences between individuals that are unexplained by fixed, additive genetic, and common environment effects. Here, the phenotypic variance $\left(V_{P}\right)$ in performance traits is decomposed into additive genetic variance $\left(\mathrm{V}_{\mathrm{A}}\right)$, common environment variance $\left(\mathrm{V}_{\mathrm{CE}}\right)$ and residual variance $\left(\mathrm{V}_{\mathrm{R}}\right)$ as:

$$
V_{P}=V_{A}+V_{C E}+V_{R}
$$

Because each individual's feather was measured multiple times, an additional individual random effect $\boldsymbol{Z}_{\boldsymbol{I}} \boldsymbol{u}_{\boldsymbol{I}}$ was fitted to capture among-individual differences in color measures. In these models, the residual component thus captures variation between measurements of the same feather (measurement error). Therefore, the phenotypic variance in color measures is here decomposed into:

$$
V_{P}=V_{A}+V_{C E}+V_{I}+V_{M E}
$$

Where $V_{I}$ is the variance between individuals (equivalent to $V_{R}$ in 2) and $V_{M E}$ the variance in measurement error.

Residuals of all animal models were approximately normally distributed (Shapiro-Wilk test values $>0.92$; Figure S3). Because of visible differences between reflectance measurements made by the two spectrometers (Figure $\mathrm{S} 1$ and Table $\mathrm{S} 1$ ), $\mathrm{V}_{\mathrm{CE}}, \mathrm{V}_{\mathrm{I}}$ and $\mathrm{V}_{\mathrm{ME}}$ of color measures were allowed to vary between these two spectrometers. This was done to assure that our inference of the average additive genetic $\mathbf{G}$ matrix for all nestling traits during the entire study period was accurate.

In all models, sex and year were fitted as categorical fixed effects to account for sexual dimorphism and between-year average differences. Sexes were pooled because cross-sex 
genetic correlations for all six traits are high and sex-specific $\mathbf{G}$ matrices are qualitatively similar (see Tables S2-S10 and Figure S4). The length of the feather vane was fitted as fixed effect covariate for all color measures, and tarsus length was included as a covariate in analyses

195

of nestling's body mass to correct for body size. The animal model was solved using Restricted Maximum Likelihood (REML) and implemented in R (R Development Core Team 2018) using the package "asreml" (Butler et al. 2009). The statistical significance of $\mathrm{V}_{\mathrm{A}}$ was tested by comparing each model with a model where $\mathrm{V}_{\mathrm{A}}$ was not estimated, using likelihood ratio tests (LRT) with one degree of freedom. Heritability was calculated as the ratio $V_{A} / V_{P}$ where $V_{P}$ did not include $\mathrm{V}_{\mathrm{ME}}$ for color measures. Uncertainty of this ratio was calculated using the delta method (Fischer et al. 2004).

To partition the covariances between traits into different components, we used a multivariate animal model, in which performance traits and individual averages of each color measure were all fitted as response variables. Using individual averages for the color traits only reduces $\mathrm{V}_{\mathrm{ME}}$ and does not alter the estimation of $\mathrm{V}_{\mathrm{A}}$. Random effects fitted in this model therefore only included additive genetic effects, common environment effects and residual errors. Fixed effects were similar to the ones used in univariate animal models, some being trait-specific. Covariances on the additive genetic level were tested individually by comparing the unconstrained models to models where these covariances were fixed to zero using LRT, with 1 degree of freedom. The estimated $\mathbf{G}$ matrix provides 15 estimates of genetic correlations between all six traits. $\mathrm{R}$ code for quantitative genetic analyses is provided in Text $\mathrm{S} 1$.

\section{Structural equation models}

We performed structural equation models (SEM) to reduce the dimensionality of the $\mathbf{G}$ matrix and investigate the general relationship between each color trait and performance. To do so, $\mathbf{G}$ matrix estimated by the six-trait animal model was first transformed into a correlation matrix 
and used as input data into different SEMs. All performance traits were reduced to a latent factor named "performance" on which they loaded positively. In these models, the variances of "performance" and of each color trait were fixed to 1 . Because a correlation matrix was used as input data, the residual variance of each indicator (here, each performance trait), which is the variance unexplained by the latent factor, was fixed to 1 minus its squared factor loading. Each SEM was fitted in R using the package "lavaan" (Rosseel 2012). Sample size in these models was set at 306 as this was the number of nestlings with at least 1 trait measured $(n=3240)$ divided by the average paternal sibship size (10.6) and thus approximates the number of families. The sample size in a SEM will not affect the inferred loadings or correlations between latent variables but impacts their uncertainty. In order to take forward the uncertainty of the $\mathbf{G}$ matrix estimates into the SEM estimates, we calculated 95\% confidence intervals (CI) of these correlations using simulation. We first simulated phenotypic data based on the population pedigree and the estimated $\mathbf{G}$ matrix using the R package "pedantics". Each simulated data set was analyzed using a multivariate animal model and the estimated $\mathbf{G}$ matrix was used as input data in a SEM. Only SEM models in which all loadings of performance traits were $>0.05$ were kept and simulations were run until obtaining 1000 estimate of correlations between each color trait and performance. This procedure excluded models in which either one loading of a performance trait on "performance" or the correlation between color and performance were abnormally high $(>10)$ while the (other) loadings were zero. This situation occurred under certain values of the $\mathbf{G}$ matrix (e.g. when low correlations switch signs) and thus, SEM estimates based on these values were discarded. As a result, the $95 \%$ CI of the average correlation between color traits and performance may not have fully incorporated the uncertainty of the $\mathbf{G}$ matrix and should not be interpreted as a test for statistical significance. $\mathrm{R}$ code for performing SEMs and simulations are provided in Text S2 and Text S3.

\section{Results}


241 All tail color and performance traits were measured in over 2800 nestlings, except the PHA response, which was measured on fewer nestlings (Table 1). Measurement repeatability of tail color was significant, although relatively low (40-50\% for brightness and UV chroma; around $30 \%$ for hue, Table S1) compared to measurement repeatability of adult color in other blue tit populations (e.g. Doutrelant et al. 2008, Figuerola et al. 1999). There was significant sexual dimorphism in these nestlings for all tail color measures but also for mass and wing length (Table S11-S16).

Heritability of tail color measures was low (1-12\%, Table 2). These color measures were negatively but not significantly correlated with each other on the genetic level (trivariate model: UV chroma-brightness: $\left.r_{G}=-0.17, \quad s e=0.36\right), \chi_{1}^{2}=0.07, p=0.78 ;$ hue-brightness: $r_{G}=-0.75$, $\mathrm{se}=0.45, \chi_{1}^{2}=2.50, \mathrm{p}=0.11$; hue-UV chroma: $\mathrm{r}_{\mathrm{G}}=-0.34, \mathrm{se}=0.54, \chi_{1}^{2}=0.37, \mathrm{p}=0.54$; Table 3 ). We hence studied color traits independently in further analyses. In contrast, heritability estimates of performance traits (body mass, wing length, and PHA response) were all moderate (19-28\%, Table 2). Heritability of PHA using repeated measures of nestlings' wing web before and after injection was also calculated (excluding measurement error) using a bivariate animal model and was close to the estimate based on individual averages $\left(h^{2}=0.16\right.$, se $=0.04$; Table S17). body mass: $\mathrm{r}_{\mathrm{G}}=0.61, \mathrm{se}=0.04, \chi_{1}^{2}=53.1, \mathrm{p}<0.001$; wing-PHA: $\mathrm{r}_{\mathrm{G}}=0.36, \mathrm{se}=0.07, \chi_{1}^{2}=30.5$, $\mathrm{p}<0.001$; body mass-wing: $\mathrm{r}_{\mathrm{G}}=0.46$, $\mathrm{se}=0.07, \chi_{1}^{2}=408.0, \mathrm{p}<0.001$; Table 3 ). These correlations were not affected by the nestlings' wing web thickness before injection (PHA- body mass: $r_{G}=0.59$, se $=0.04$; wing-PHA: $r_{G}=0.36$, se=0.07; body mass-wing: $r_{G}=0.43$, se $=0.06$ ). S22). 
Regarding genetic correlations between coloration and performance traits, inspection of the $\mathbf{G}$ matrix (highlighted part in Table 3 ) shows that UV chroma is consistently negatively correlated with performance traits. In contrast, the signs of the genetic correlations between the two other color measures and performance traits are inconsistent. Separate SEMs were run for each color trait independently, to estimate its average correlation with performance. These analyses indicated that tail brightness was (largely) positively (coefficient $=0.39 ; 95 \% \mathrm{CI}=-0.09-1.00$ ), and UV chroma negatively (coefficient $=-0.69 ; 95 \% \mathrm{CI}=-1.36--0.15$ ) correlated with performance. For hue, this correlation was weakly negative (coefficient $=-0.12 ; 95 \% \mathrm{CI}=-$ $0.81-0.40$, Figure S5).

\section{Discussion}

In this study, we used long-term nestling data, pedigree information and a cross-fostering design to estimate additive genetic variation in coloration measures, performance traits and genetic correlations between them, and find evidence for indirect benefits of blue tail coloration in wild blue tits.

Tail color measures had a low heritability which is in line with other heritability estimates of carotenoid and structural coloration in blue tits (Evans \& Sheldon 2012, Hadfield et al. 2006, Drobniak et al. 2013, Charmantier et al. 2017). In contrast, heritability of performance traits (body mass, wing length, and PHA response) was generally moderate and within the range of what was found in other populations or species (see e.g. Merilä \& Sheldon 2000, Merilä et al. 2001, Hadfield et al. 2007 for morphometric traits, and Pitala et al.2007, Kim et al. 2013 for PHA response). In addition all performance traits were positively correlated on the genetic level, which is consistent with previous estimates of genetic correlations between mass and wing length (e.g. Björklund et al. 2013) and between mass and PHA response (Kim et al. 2013) and indicates the presence of additive genetic variation for individual performance. Using 
SEMs, we found that the average genetic correlation between each color measure and a latent factor "performance", was positive for tail brightness, negative for UV chroma, and weakly negative for hue.

Hence, our findings suggest indirect fitness benefits of choosing mates with tails that are brighter or reflecting less in the UV. Indeed, all three performance traits are known to be positively associated with fitness. While the positive effects of mass at fledging on survival have been well documented (e.g. Perrins 1965, Tinbergen \& Boerlijst 1990, Lindén et al. 1992, Radersma et al. 2015), wing length was shown to determine fledging date (Radersma et al. 2011), and impact recruitment probability (Verboven \& Visser 1998), possibly through competitive advantage or decreased predation risk. PHA can also be considered an important functional trait as it was shown to increase survival and recruitment probability of nestlings in various species (Hõrak et al. 1999, Moreno et al. 2005, Cichoń \& Dubiec 2005, López-Rull et al. 2011), although this relationship may be due to its condition-dependence (Alonso-Alvarez \& Tella 2001, Thompson et al. 2014). Nevertheless, PHA, body mass and wing length were heritable and genetically correlated, which suggests that their genetic architecture "captures the so-called good genes" and allow sexual selection for indirect benefits to occur in this population. Because tail color indicates immune response through its genetic relationship with performance, our results also support the PMSS hypothesis.

Previous studies showed that bluer plumage ornaments are condition-dependent in juveniles (Johnsen et al. 2003, Jacot \& Kempenaers 2007, Peters et al. 2007 in blue tits, Siefferman et al. 2008, Siefferman \& Hill 2007 in other species) and in adults (Doutrelant et al. 2012, Beck et al. 2015, Galván 2011), which contrasts with the negative genetic association that we found between hue, UV chroma, and performance traits. Importantly, correlations between hue, UV chroma and performance traits were also negative on the phenotypic level (Table S23). This negative relationship implies that developing bluer tails early in life has costs which can impact 
313 individuals' probability to recruit. However, these fitness costs may be offset on the first reproductive year, if yearlings with a bluer tail are sexually more attractive than duller yearlings.

315 On the other hand, genetic correlations between hue, UV chroma and performance should be interpreted with caution given the very low heritability of both color measures and the high

317 uncertainty of their additive genetic variance estimates.

In the context of sexual selection based on indirect benefits, key parameters are the (square root) heritability of the sexually selected trait, additive genetic variance in fitness and genetic correlation between this trait and fitness (Kirkpatrick and Barton 1997). This means that, for mate choice based on indirect benefits of an ornament to evolve, this ornament has to provide sufficient information regarding an individual's genotype. Because we found low heritability for tail color measures, our results imply that indirect sexual selection on mate choice for this ornament will be a weak evolutionary force (cf. Møller \& Alatalo 1999, Qvarnström et al. 2006).

Despite broad interest in understanding the evolution of animal ornaments, studies estimating

327 heritability of coloration and its genetic correlation with performance to test the indirect benefits 328 hypothesis remain rare. This study provides evidence for additive genetic variation in tail coloration and performance and for a genetic association between them. More specifically, our

330 findings suggest that mate choice based on tail brightness and UV chroma can have fitness payoffs in blue tits and hence support indirect benefits of mate choice for this ornament.

332 However, because of the low heritability of tail structural coloration, this mechanism may not 333 be a major driver of its evolution. 


\section{References}

Alonso-Alvarez, C., \& Tella, J. L. (2001). Effects of experimental food restriction and bodymass changes on the avian T-cell-mediated immune response. Canadian Journal of Zoology, 79(1), 101-105. https://doi.org/10.1139/z00-190

Alonso-Alvarez, C., Doutrelant, C., \& Sorci, G. (2004). Ultraviolet reflectance affects malemale interactions in the blue tit (Parus caeruleus ultramarinus). Behavioral Ecology, 15(5), 805-809. https://doi.org/10.1093/beheco/arh083

Amundsen, T. (2000). Why are female birds ornamented? Trends in Ecology \& Evolution, 15(4), 149-155.

Andersson, S., Ornborg, J., \& Andersson, M. (1998). Ultraviolet sexual dimorphism and assortative mating in blue tits. Proceedings of the Royal Society of London B: Biological Sciences, 265(1395), 445-450. https://doi.org/10.1098/rspb.1998.0315

Beck, M. L., Hopkins, W. A., \& Hawley, D. M. (2015). Relationships among plumage coloration, blood selenium concentrations and immune responses of adult and nestling tree swallows. Journal of Experimental Biology, 218(21), 3415-3424. https://doi.org/10.1242/jeb.123794

Birkhead, T. R., Pellatt, E. J., Matthews, I. M., Roddis, N. J., Hunter, F. M., McPhie, F., \& Castillo-Juarez, H. (2006). Genic capture and the genetic basis of sexually selected traits in the zebra finch. Evolution, 60(11), 2389-2398.

Bonneaud, C., Sinsheimer, J. S., Richard, M., Chastel, O., \& Sorci, G. (2009). Mhc polymorphisms fail to explain the heritability of phytohaemagglutinin- induced skin swelling in a wild passerine. Biology Letters, 5(6), 784-787. https://doi.org/10.1098/rsbl.2009.0435

Brommer, J. E., Alho, J. S., Biard, C., Chapman, J. R., Charmantier, A., Dreiss, A., ... Winkel, W. (2010). Passerine extrapair mating dynamics: a bayesian modeling approach comparing four species. The American Naturalist, 176(2), 178-187. https://doi.org/10.1086/653660

Brommer, J. E., \& Kluen, E. (2012). Exploring the genetics of nestling personality traits in a wild passerine bird: testing the phenotypic gambit. Ecology and Evolution, 2(12), 30323044. https://doi.org/10.1002/ece3.412

Butler, D. G., Cullis, B. R., Gilmour, A. R., \& Gogel, B. J. (2009). ASReml-R reference manual. Department of Primary Industries and Fisheries, State of Queensland, Australia.

Charmantier, A., Wolak, M. E., Grégoire, A., Fargevieille, A., \& Doutrelant, C. (2017). Colour ornamentation in the blue tit: quantitative genetic (co)variances across sexes. Heredity, 118, 125-134. https://doi.org/10.1038/hdy.2016.70 
Charmantier, A., \& Réale, D. (2005). How do misassigned paternities affect the estimation of heritability in the wild? Molecular Ecology, 14, 2839-2850. https://doi.org/10.1111/j.1365-294X.2005.02619.x

Cichoń, M., \& Dubiec, A. (2005). Cell-mediated immunity predicts the probability of local recruitment in nestling blue tits. Journal of Evolutionary Biology, 18(4), 962-966. https://doi.org/10.1111/j.1420-9101.2005.00910.x

Coster, A.(2012). pedigree: Pedigree functions. R package version 1.4.https://CRAN.Rproject.org/package= $=$ pedigree

Doutrelant, C., Gregoire, A., Grnac, N., Gomez, D., Lambrechts, M., \& Perret, P. (2008). Female coloration indicates female reproductive capacity in blue tits. Journal of Evolutionary Biology, 21, 226-233. https://doi.org/10.1111/j.1420-9101.2007.01451.x

Doutrelant, C., Grégoire, A., Midamegbe, A., Lambrechts, M., \& Perret, P. (2012). Female plumage coloration is sensitive to the cost of reproduction. An experiment in blue tits. Journal of Animal Ecology, 81(1), 87-96. https://doi.org/10.1111/j.13652656.2011.01889.x

Drobniak, S. M., Wiejaczka, D., Arct, A., Dubiec, A., \& Gustafsson, L. (2013). Low crosssex genetic correlation in carotenoid-based plumage traits in the blue tit nestlings (Cyanistes caeruleus). PLoS ONE, 8(7), e69786. https://doi.org/10.1371/journal.pone.0069786

Evans, S. R., \& Sheldon, B. C. (2012). Quantitative genetics of a carotenoid-based color : heritability and persistent natal environmental effects in the great tit. The American Naturalist, 1, 79-94. https://doi.org/10.1086/663198

Figuerola, J., Senar, J. C., \& Pascual, J. (1999). The use of a colorimeter in field studies of blue tit Parus caeruleus coloration. Ardea, 87(2), 269-275.

Fischer, T. M., Gilmour, A. R., \& Werf, J. H. Van Der. (2004). Computing approximate standard errors for genetic parameters derived from random regression models fitted by average information REML. Genetics, Selection, Evolution: GSE, 36(3), 363-369. https://doi.org/10.1186/1297-9686-36-3-363

Galván, I. (2011). Ultraviolet-blue plumage colouration can be perceived as an indicator of fluctuating asymmetry by blue tits (Cyanistes caeruleus). Journal of Ornithology, 152(2), 223-230. https://doi.org/10.1007/s10336-010-0568-y

Hadfield, J. D., Nutall, A., Osorio, D., \& Owens, I. P. F. (2007). Testing the phenotypic gambit: phenotypic, genetic and environmental correlations of colour. Journal of Evolutionary Biology, 20(2), 549-557. https://doi.org/10.1111/j.14209101.2006.01262.x

Hadfield, J. D., Burgess, M. D., Lord, A., Phillimore, A. B., Clegg, S. M., \& Owens, I. P. F. (2006). Direct versus indirect sexual selection : genetic basis of colour, size and recruitment in a wild bird. Proceedings of the Royal Society of London B: Biological Sciences, 273, 1347-1353. https://doi.org/10.1098/rspb.2005.3459 
Hamilton, W. D., \& Zuk, M. (1982). Heritable true fitness and bright birds: a role for parasites? Science, 218, 384-386.

Hõrak, P., Tegelmann, L., Ots, I., \& Møller, A. P. (1999). Immune function and survival of great tit nestlings in relation to growth conditions. Oecologia, 121, 316-322. https://doi.org/10.1007/978-3-642-38865-1_45

Hunt, S., Bennett, A. T. D., Cuthill, I. C., \& Griffiths, R. (1998). Blue tits are ultraviolet tits. Proceedings of the Royal Society of London B: Biological Sciences, 265, 451-455.

Hunt, S., Cuthill, I. C., Bennett, A. T. D., \& Griffiths, R. (1999). Preferences for ultraviolet partners in the blue tit. Animal Behaviour, 58(4), 809-815. https://doi.org/10.1006/anbe.1999.1214

Jacot, A., \& Kempenaers, B. (2007). Effects of nestling condition on UV plumage traits in blue tits: An experimental approach. Behavioral Ecology, 18(1), 34-40. https://doi.org/10.1093/beheco/arl054

Johnsen, A., Delhey, K., Andersson, S., \& Kempenaers, B. (2003). Plumage colour in nestling blue tits : sexual dichromatism, condition dependence and genetic effects. Proceedings of the Royal Society of London B: Biological Sciences, 270, 1263-1270. https://doi.org/10.1098/rspb.2003.2375

Jones, A. G., \& Ratterman, N. L. (2009). Mate choice and sexual selection : What have we learned since Darwin? Proceedings in the National Academy of Sciences, 106(S1), 10001-10008.

Kim, S.-Y., Fargallo, J. A., Vergara, P., \& Martínez-Padilla, J. (2013). Multivariate heredity of melanin-based coloration, body mass and immunity. Heredity, 111, 139-146. https://doi.org/10.1038/hdy.2013.29

Kinnard, T. B., \& Westneat, D. F. (2009). Phenotypic and genetic variance of house sparrows (Passer domesticus) early in development. The Auk, 126(4), 884-895. https://doi.org/10.1525/auk.2009.08119

Kirkpatrick, M., \& Barton, N. H. (1997). The strength of indirect selection on female mating preferences. Proceedings of the National Academy of Sciences of the United States of America, 94(4), 1282-1286. https://doi.org/VL - 94

Kruuk, L. E. B., \& Hadfield, J. D. (2007). How to separate genetic and environmental causes of similarity between relatives. Journal of Evolutionary Biology, 20(5), 1890-1903. https://doi.org/10.1111/j.1420-9101.2007.01377.x

Linden, M., Gustafsson, L., \& Part, T. (1992). Selection of fledging mass in the collared flycatcher and the great tit. Ecology. https://doi.org/10.2307/1938745

López-Rull, I., Celis, P., Salaberria, C., Puerta, M., \& Gil, D. (2011). Post-fledging recruitment in relation to nestling plasma testosterone and immunocompetence in the spotless starling. Functional Ecology, 25(3), 500-508. https://doi.org/10.1111/j.13652435.2010.01783.x 
Merilä, J., Kruuk, L. E. B., \& Sheldon, B. C. (2001). Natural selection on the genetical component of variance in body condition in a wild bird population. Journal of Evolutionary Biology, 14, 918-929.

Merilä, J., \& Sheldon, B. C. (2000). Lifetime reproductive success and heritability in nature. The American Naturalist, 155(3), 301-310. https://doi.org/10.1086/303330

Monrós, J. S., Belda, E. J., \& Barba, E. (2002). Post-fledging survival of individual great tits : the effect of hatching date and fledging mass. Oikos, 99, 481-488.

Moreno, J., Merino, S., Sanz, J. J., Arriero, E., Morales, J., \& Tomás, G. (2005). Nestling cell-mediated immune response, body mass and hatching date as predictors of local recruitment in the pied flycatcher Ficedula hypoleuca. Journal of Avian Biology, 36(3), 251-260. https://doi.org/10.1111/j.0908-8857.2005.03413.x

Morrissey, M. (2018). pedantics: Functions to Facilitate Power and Sensitivity Analyses for Genetic Studies of Natural Populations. R package version 1.7. https://CRAN.Rproject.org/package $=$ pedantics

Norris, K. (1993). Heritable variation in a plumage indicator of viability in male great tits (Parus major). Nature, 362, 537-539.

Perrins, C. M. (1965). Population Fluctuations and Clutch-Size in the Great Tit, Parus major L. Journal of Animal Ecology, 34(3), 601-647.

Peters, A., Delhey, K., Johnsen, A., \& Kempenaers, B. (2007). The condition-dependent development of carotenoid-based and structural plumage in nestling blue tits : males and females differ. The American Naturalist, 169, S122-S136.

Pickett, S. R. A., Weber, S. B., Mcgraw, K. J., Norris, K. J., \& Evans, M. R. (2013). Environmental and parental influences on offspring health and growth in great tits (Parus major). PLoS ONE, 8(7), e69695. https://doi.org/10.1371/journal.pone.0069695

Pitala, N., Gustafsson, L., Sendecka, J., \& Brommer, J. E. (2007). Nestling immune response to phytohaemagglutinin is not heritable in collared flycatchers. Biology Letters, 3, 418421. https://doi.org/10.1098/rsbl.2007.0135

Qvarnström, A., Brommer, J. E., \& Gustafsson, L. (2006). Evolution of mate choice in the wild. Nature, 441, 84-86. https://doi.org/10.1038/nature05501

Radersma, R., Komdeur, J., \& Tinbergen, J. M. (2015). Early morning fledging improves recruitment in Great Tits Parus major. Ibis, 157(2), 351-355. https://doi.org/10.1111/ibi.12230

Radersma, R., Tinbergen, J. M., \& Komdeur, J. (2011). Do brood sex ratio, nestling development and sex affect fledging timing and order? An experimental study on great tits. Animal Behaviour, 81(1), 69-75. https://doi.org/10.1016/j.anbehav.2010.09.007 
Reid, J. M. (2014). Quantitative genetic approaches to understanding sexual selection and mating system evolution in the wild. In A. Charmantier, D. Garant, \& L. E. B. Kruuk (Eds.), Quantitative Genetics in the Wild (pp. 34-53). Oxford: Oxford University Press.

Remeš, V., \& Matysioková, B. (2013). More ornamented females produce higher-quality offspring in a socially monogamous bird : an experimental study in the great tit (Parus major). Frontiers in Zoology, 10(14), 1-10.

Rémy, A., Grégoire, A., Perret, P., \& Doutrelant, C. (2010). Mediating male-male interactions: The role of the UV blue crest coloration in blue tits. Behavioral Ecology and Sociobiology, 64(11), 1839-1847. https://doi.org/10.1007/s00265-010-0995-z

Rosseel, Y. (2012). lavaan: An R Package for Structural Equation Modeling. Journal of Statistical Software, 48(2), 1-36. http://www.jstatsoft.org/v48/i02/.

Sakaluk, S. K., Wilson, A. J., Bowers, E. K., Johnson, L. S., Masters, B. S., Johnson, B. G., ... Thompson, C. F. (2014). Genetic and environmental variation in condition, cutaneous immunity, and haematocrit in house wrens. BMC Evolutionary Biology, 14, 242. https://doi.org/10.1186/s12862-014-0242-8

Senar, J. C., Figuerola, J., \& Pascual, J. (2002). Brighter yellow blue tits make better parents. Proceedings of the Royal Society of London B: Biological Sciences, 269, 257-261. https://doi.org/10.1098/rspb.2001.1882

Siefferman, L., \& Hill, G. E. (2007). The effect of rearing environment on blue structural coloration of eastern bluebirds (Sialia sialis). Behavioral Ecology and Sociobiology, 61(12), 1839-1846. https://doi.org/10.1097/IOP.0b013e3181d3da43.Risk

Siefferman, L., Shawkey, M. D., Bowman, R., \& Woolfenden, G. E. (2008). Juvenile coloration of Florida scrub-jays (Aphelocoma coerulescens) is sexually dichromatic and correlated with condition. Journal of Ornithology, 149(3), 357-363. https://doi.org/10.1007/s10336-008-0289-7

Smits, J. E., Bortolotti, G. R., \& Tella, J. L. (1999). Simplifying the phytohaemagglutinin skin-testing technique in studies of avian immunocompetence. Functional Ecology, 13(4), 567-572. https://doi.org/10.1046/j.1365-2435.1999.00338.x

Svensson, L. (1992). Identification guide to European passerines. Stockholm.

Thompson, C. F., Sakaluk, S. K., Masters, B. S., Johnson, B. G. P., Vogel, L. A., Forsman, A. M., \& Johnson, L. S. (2013). Condition-dependent sex difference in nestling house wren (Troglodytes aedon) response to phytohaemagglutinin injection. Canadian Journal of Zoology, 92, 1-7. https://doi.org/10.1139/cjz-2013-0140

Tinbergen, J., \& Boerlijst, M. (1990). Nestling weight and survival in individual great tits (Parus major). Journal of Animal Ecology, 59(3), 1113-1127.

Velando, A., Torres, R., \& Espinosa, I. (2005). Male coloration and chick condition in bluefooted booby : a cross-fostering experiment. Behavioral Ecology and Sociobiology, 58, 175-180. https://doi.org/10.1007/s00265-005-0911-0 
519 Verboven, N., \& Visser, M. E. (1998). Seasonal variation in local recruitment of great tits: The Importance of Being Early. Oikos, 81, 511-524. https://doi.org/10.2307/3546771

521 Wilson, A. J., Réale, D., Clements, M. N., Morrissey, M. M., Postma, E., Walling, C. A., ... Nussey, D. H. (2009). An ecologist's guide to the animal model. The Journal of Animal Ecology, 79(1), 13-26. https://doi.org/10.1111/j.1365-2656.2009.01639.x 


\section{Supporting information}

525

526 Table S1: Repeatability of each color trait measured by each spectrometer

527 Figure S1: Average reflectance spectrum measured by each spectrometer

528 Figure S2: Distribution of the six traits measured in nestlings

529 Figure S3: Distribution of the univariate animal model residuals for all six traits

530 Tables S2-S7: Sex-specific variances and cross-sex covariances estimated by bivariate animal models for each trait separately

532 Figure S4: Additive genetic variances of all six traits and their covariances in males and females

533 TablesS8-S9: Genetic correlation matrix estimated by a multivariate mixed model in females 534 and males respectively.

535 Table S10: Cross-sex genetic correlation and SE for each trait

536 Tables S11-S16: Fixed and random effects estimated by the animal model for each trait

537 Tables S17: Variances of wing web thickness measured on day 13 and day 14 and their covariances estimated on different levels by a bivariate animal model

539 Tables S18-S22: Covariance matrices derived from the multivariate animal model

540 Figure S5: Correlations and loadings estimated in the structural equation models

541 Tables S23: Phenotypic correlation matrix derived from a multivariate mixed model

542 Text S1: R code for performing quantitative genetic analyses

543 Text S2-S3: R code for performing structural equation modelling and simulations 
544 Table 1: Number of individuals, rearing broods, mean and standard deviation (SD) for each

545 studied trait.

546

\begin{tabular}{|lllllll|}
\hline & Brightness & Hue & UV chroma & PHA & Body mass & Wing \\
\hline n.individuals & 2851 & 2851 & 2851 & 1516 & 3210 & 3200 \\
n.broods & 364 & 364 & 364 & 173 & 390 & 389 \\
mean (SD) & $9.46(2.74)$ & $340.78(10.61)$ & $0.33(0.02)$ & $0.54(0.17)$ & $11.40(1.08)$ & $46.34(3.39)$ \\
\hline
\end{tabular}

547 Table 2: Animal model estimates (and standard errors) of variance components of all six traits.

548 Heritability $\left(h^{2}\right)$ and ratio $\mathrm{V}_{\mathrm{CE}} / \mathrm{V}_{\mathrm{P}}$ (and their standard error) were calculated for each trait, where

$549 V_{P}$ is the sum of all estimated variances, except for color traits where it does not include $V_{M E}$

550 For tail color traits, $\mathrm{V}_{\mathrm{I}}, \mathrm{V}_{\mathrm{CE}}$ and $\mathrm{V}_{\mathrm{ME}}$ were estimated separately for each spectrophotometer used

551 (1 and 2 respectively) and thus two $h^{2}$ and ratios $\mathrm{V}_{\mathrm{CE}} / \mathrm{V}_{\mathrm{P}}$ were calculated.

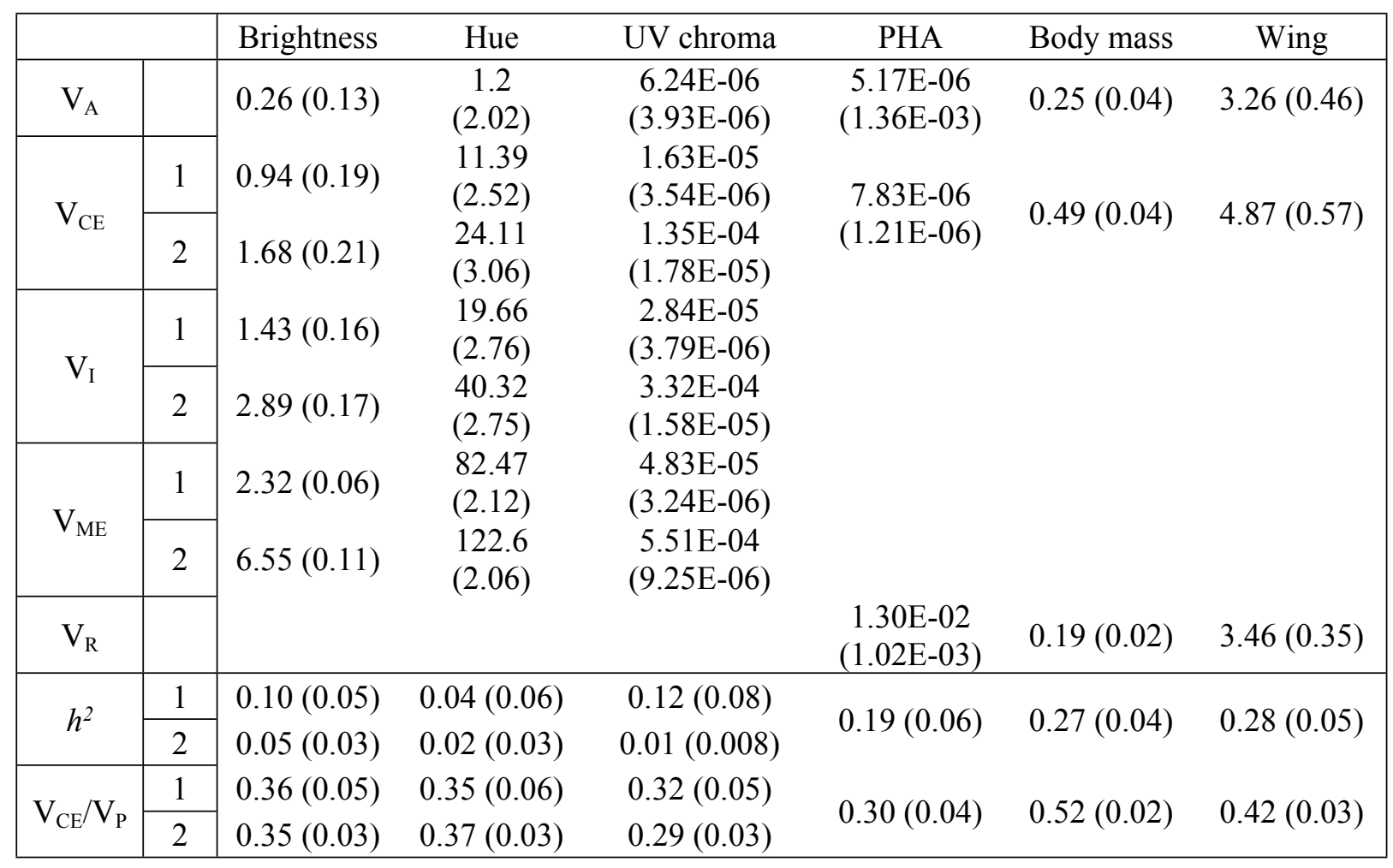


553 Table 3: Additive genetic correlation (and standard error) matrix estimated by the multivariate

554 animal model. Correlations between color measures and performance traits are highlighted in 555 grey.

\begin{tabular}{|cccccc|}
\hline Brightness & Hue & UV chroma & PHA & Body mass & Wing \\
\hline & & & & & \\
$-0.72(0.40)$ & & & & & \\
$-0.13(0.41)$ & $-0.34(0.54)$ & & & & \\
$-0.05(0.25)$ & $-0.04(0.30)$ & $-0.50(0.33)$ & & & \\
$0.21(0.20)$ & $0.13(0.23)$ & $-0.17(0.28)$ & $0.23(0.16)$ & & \\
$0.50(0.24)$ & $-0.51(0.28)$ & $-0.35(0.35)$ & $0.32(0.19)$ & $0.26(0.13)$ & \\
\hline
\end{tabular}




\section{Supplementary material belonging to the article}

\section{"Tail color signals performance in blue tit nestlings"}

Table S1: Repeatability of each color measured by each spectrometer

\begin{tabular}{|l|l|l|}
\hline Trait & Repeatability 1 $(95 \% \mathrm{Cl})$ & Repeatability 2 $(95 \% \mathrm{Cl})$ \\
\hline brightness & $0.51(0.48-0.55)$ & $0.40(0.38-0.43)$ \\
\hline hue & $0.28(0.32-0.25)$ & $0.33(0.31-0.36)$ \\
\hline UV chroma & $0.50(0.47-0.54)$ & $0.43(0.41-0.45)$ \\
\hline
\end{tabular}

Figure S1: Average reflectance spectra from nestlings' tail feathers in 2005-2006 (first spectrometer, red line), and in 2003+2007-2009 (second spectrometer, blue line). The dotted vertical line represents the peak reflectance for both spectrophotometers.

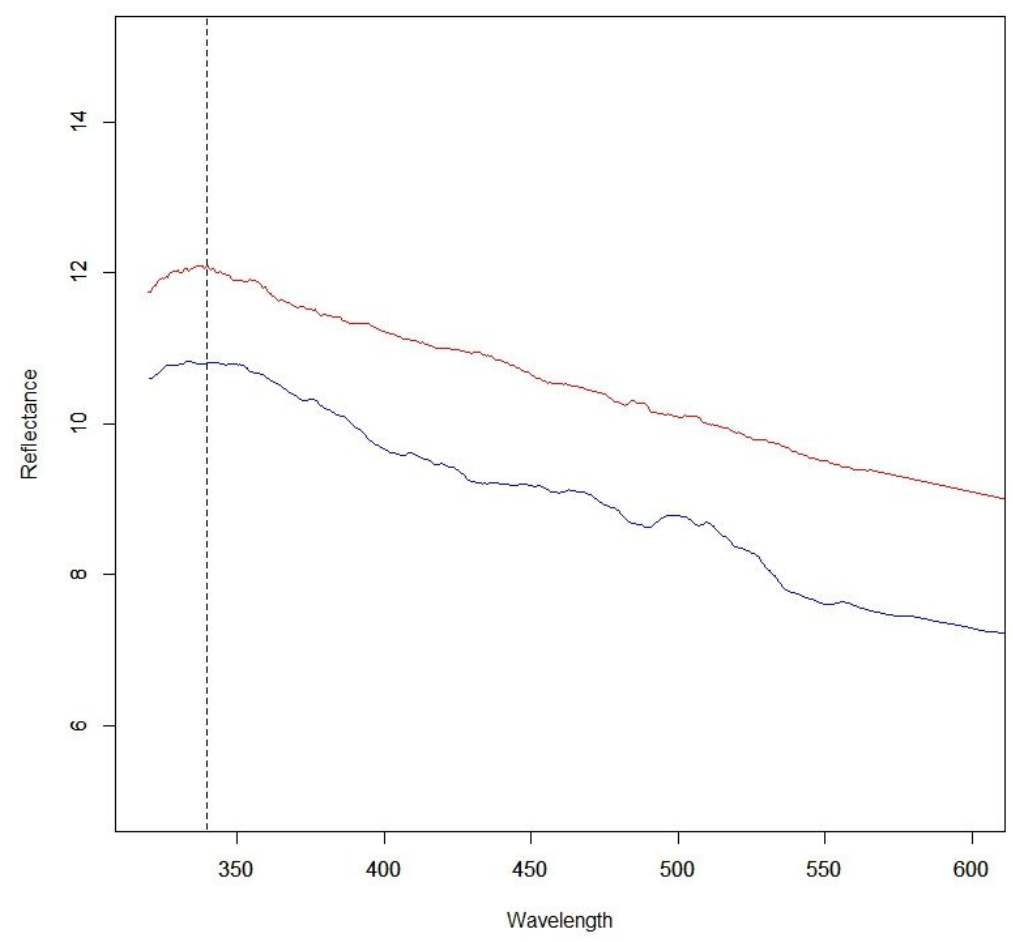


Figure S2: Distribution of the six traits (averages per individual) measured in nestlings.

Hue

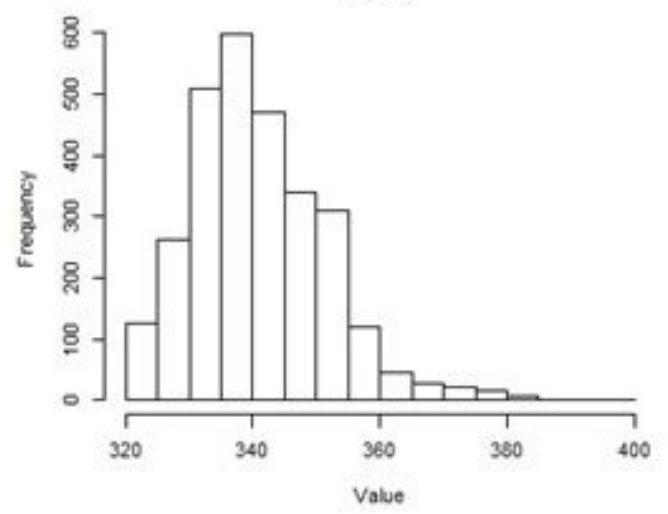

UV chroma

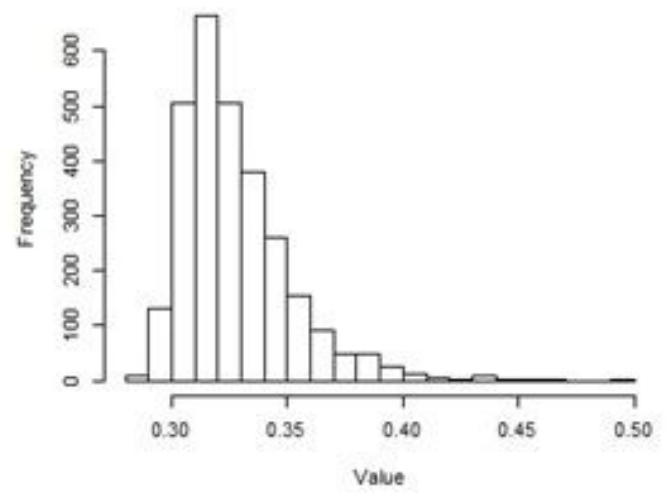

Body mass

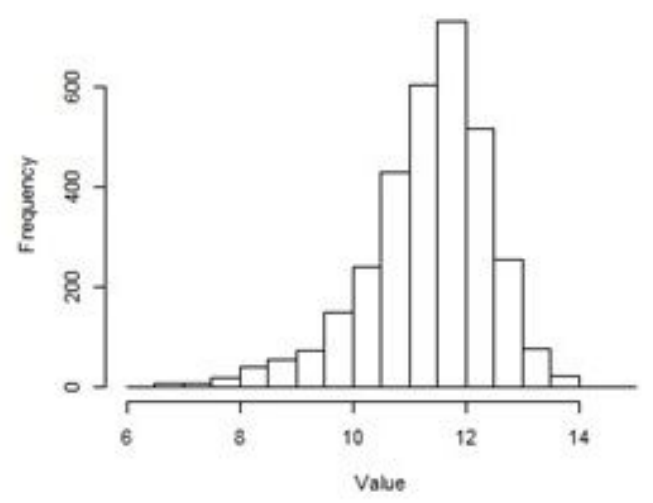

Brightness

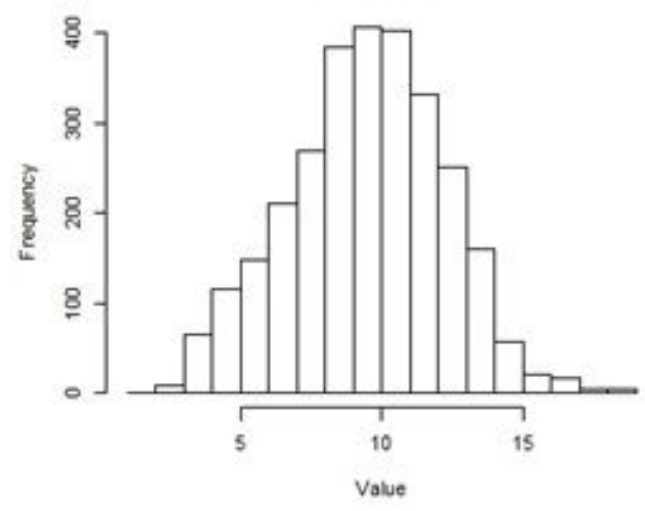

PHA

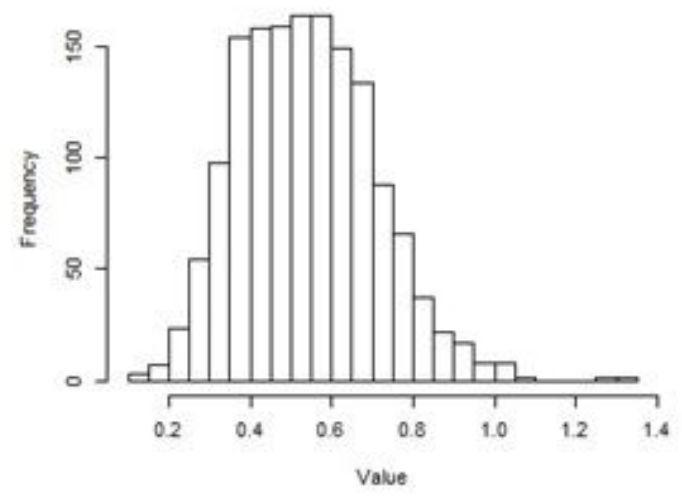

Wing length

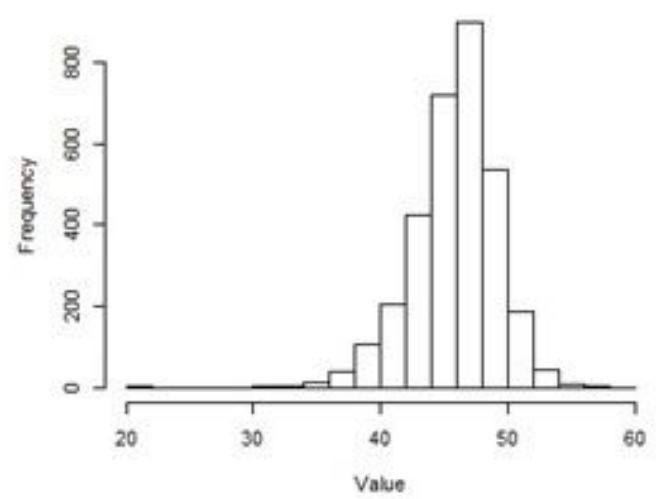


Figure S3: Distribution of the univariate animal model residuals for all six traits
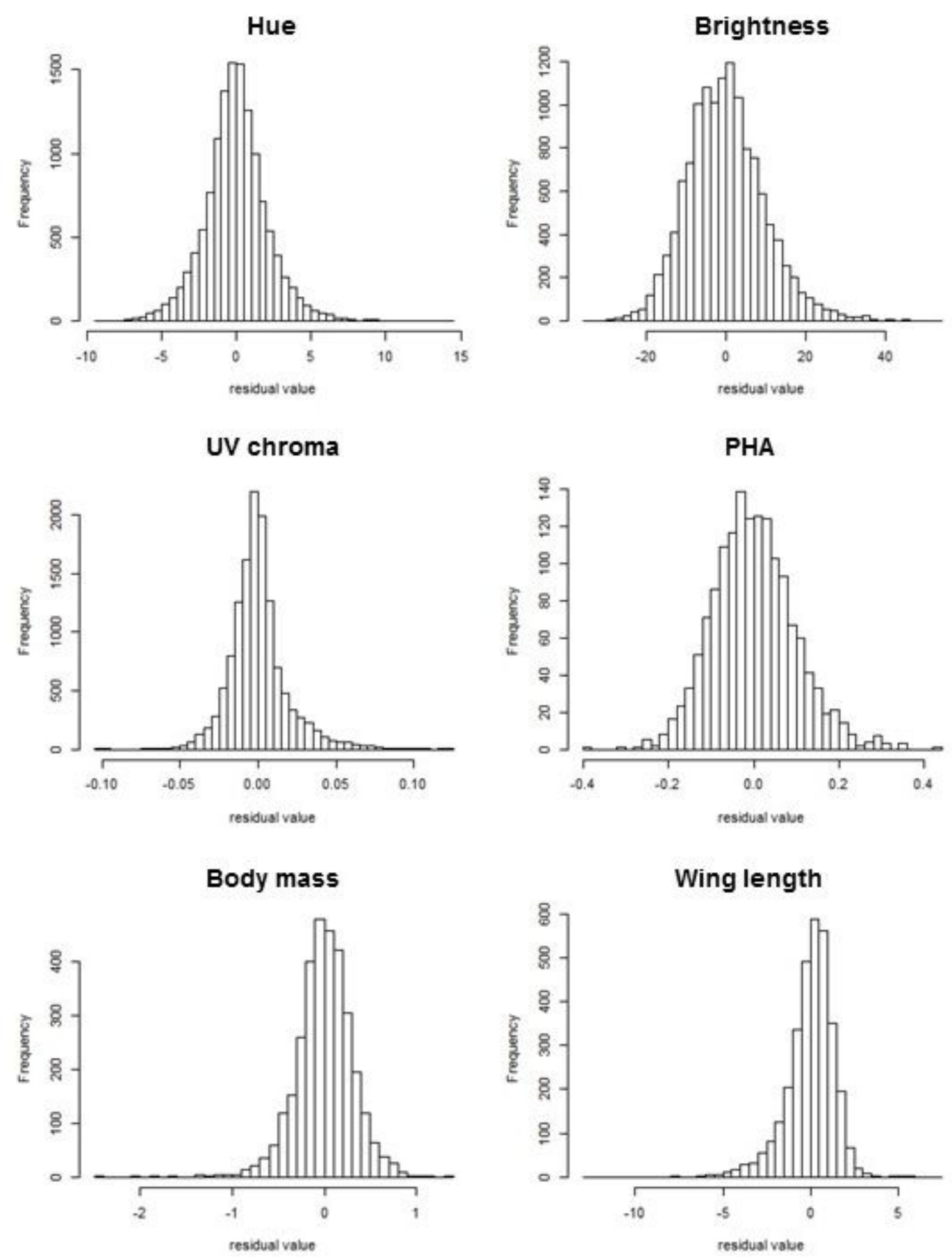
Table S2: Variances and covariances, their standard error (SE), and z ratio, estimated by a bivariate animal model with tail brightness in males and in females as two response variables. Common environment and residual error variances were estimated separately for each spectrophotometer (1: feathers from 2005-2006, 2: feathers from 2003, 2007-2009).

\begin{tabular}{|ccccc|}
\hline Component & Parameter & Estimate & SE & z.ratio \\
\hline \multirow{3}{*}{ Common environment 1 } & $\mathrm{V}_{\mathrm{m}}$ & 1.12 & 0.26 & 4.40 \\
& $\mathrm{COV}_{\mathrm{mf}}$ & 0.90 & 0.20 & 4.49 \\
& $\mathrm{~V}_{\mathrm{f}}$ & 0.78 & 0.23 & 3.35 \\
\hline \multirow{3}{*}{ Common environment 2 } & $\mathrm{V}_{\mathrm{m}}$ & 1.50 & 0.27 & 5.60 \\
& $\mathrm{COV}_{\mathrm{mf}}$ & 1.68 & 0.24 & 6.99 \\
& $\mathrm{~V}_{\mathrm{f}}$ & 2.00 & 0.34 & 5.85 \\
\hline \multirow{3}{*}{ Additive genetic } & $\mathrm{V}_{\mathrm{m}}$ & 0.22 & 0.19 & 1.21 \\
& $\mathrm{COV}_{\mathrm{mf}}$ & 0.31 & 0.17 & 1.85 \\
& $\mathrm{~V}_{\mathrm{f}}$ & 0.45 & 0.29 & 1.56 \\
\hline \multirow{2}{*}{ Residual 1 } & $\mathrm{V}_{\mathrm{m}}$ & 1.65 & 0.21 & 7.76 \\
& $\mathrm{~V}_{\mathrm{f}}$ & 2.08 & 0.31 & 6.72 \\
\hline \multirow{2}{*}{ Residual 2 } & $\mathrm{V}_{\mathrm{m}}$ & 4.36 & 0.26 & 16.57 \\
& $\mathrm{~V}_{\mathrm{f}}$ & 4.89 & 0.33 & 14.94 \\
\hline
\end{tabular}

Table S3: Variances and covariances, their standard error (SE), and z ratio, estimated by a bivariate animal model with tail hue in males and in females as two response variables. Common environment and residual error variances were estimated separately for each spectrophotometer (1: feathers from 2005-2006, 2: feathers from 2003, 2007-2009).

\begin{tabular}{|ccccc|}
\hline Component & Parameter & Estimate & SE & z.ratio \\
\hline \multirow{3}{*}{ Common environment 1 } & $\mathrm{V}_{\mathrm{m}}$ & 11.81 & 4.17 & 2.83 \\
& $\mathrm{COV}_{\mathrm{mf}}$ & 12.38 & 3.38 & 3.67 \\
& $\mathrm{~V}_{\mathrm{f}}$ & 17.87 & 4.69 & 3.81 \\
\hline \multirow{3}{*}{ Common environment 2 } & $\mathrm{V}_{\mathrm{m}}$ & 29.72 & 4.96 & 5.99 \\
& $\mathrm{COV}_{\mathrm{mf}}$ & 24.48 & 3.78 & 6.48 \\
& $\mathrm{~V}_{\mathrm{f}}$ & 20.29 & 4.68 & 4.34 \\
\hline \multirow{3}{*}{ Additive genetic } & $\mathrm{V}_{\mathrm{m}}$ & 4.96 & 4.96 & 1.00 \\
& $\mathrm{COV}_{\mathrm{mf}}$ & 4.94 & 4.00 & 1.24 \\
& $\mathrm{~V}_{\mathrm{f}}$ & 14.25 & 5.58 & 2.56 \\
\hline \multirow{2}{*}{ Residual 1 } & $\mathrm{V}_{\mathrm{m}}$ & 49.27 & 6.09 & 8.09 \\
& $\mathrm{~V}_{\mathrm{f}}$ & 25.05 & 5.32 & 4.71 \\
\hline \multirow{2}{*}{ Residual 2 } & $\mathrm{V}_{\mathrm{m}}$ & 71.25 & 4.96 & 14.36 \\
& $\mathrm{~V}_{\mathrm{f}}$ & 80.45 & 5.79 & 13.90 \\
\hline
\end{tabular}


Table S4: Variances and covariances, their standard error (SE), and z ratio, estimated by a bivariate animal model with tail UV chroma in males and in females as two response variables. Common environment and residual error variances were estimated separately for each spectrophotometer (1: feathers from 2005-2006, 2: feathers from 2003, 2007-2009).

\begin{tabular}{|ccccc|}
\hline Component & Parameter & Estimate & SE & z.ratio \\
\hline \multirow{3}{*}{ Common environment 1 } & $\mathrm{V}_{\mathrm{f}}$ & $1.26 \mathrm{E}-05$ & $3.95 \mathrm{E}-06$ & 3.20 \\
& $\mathrm{COV}_{\mathrm{mf}}$ & $1.67 \mathrm{E}-05$ & $3.83 \mathrm{E}-06$ & 4.35 \\
& $\mathrm{~V}_{\mathrm{m}}$ & $2.20 \mathrm{E}-05$ & $5.62 \mathrm{E}-06$ & 3.91 \\
\hline \multirow{3}{*}{ Common environment 2 } & $\mathrm{V}_{\mathrm{f}}$ & $1.34 \mathrm{E}-04$ & $2.64 \mathrm{E}-05$ & 5.07 \\
& $\mathrm{COV}_{\mathrm{mf}}$ & $1.43 \mathrm{E}-04$ & $2.09 \mathrm{E}-05$ & 6.84 \\
& $\mathrm{~V}_{\mathrm{m}}$ & $1.58 \mathrm{E}-04$ & $2.65 \mathrm{E}-05$ & 5.96 \\
\hline \multirow{3}{*}{ Additive genetic } & $\mathrm{V}_{\mathrm{f}}$ & $1.21 \mathrm{E}-05$ & $7.45 \mathrm{E}-06$ & 1.63 \\
& $\mathrm{COV}_{\mathrm{mf}}$ & $1.21 \mathrm{E}-05$ & $5.75 \mathrm{E}-06$ & 2.11 \\
& $\mathrm{~V}_{\mathrm{m}}$ & $1.22 \mathrm{E}-05$ & $8.14 \mathrm{E}-06$ & 1.50 \\
\hline \multirow{2}{*}{ Residual 1 } & $\mathrm{V}_{\mathrm{f}}$ & $2.75 \mathrm{E}-05$ & $6.23 \mathrm{E}-06$ & 4.42 \\
& $\mathrm{~V}_{\mathrm{m}}$ & $3.63 \mathrm{E}-05$ & $6.98 \mathrm{E}-06$ & 5.20 \\
\hline \multirow{2}{*}{ Residual 2 } & $\mathrm{V}_{\mathrm{f}}$ & $5.02 \mathrm{E}-04$ & $2.70 \mathrm{E}-05$ & 18.58 \\
& $\mathrm{~V}_{\mathrm{m}}$ & $4.29 \mathrm{E}-04$ & $2.32 \mathrm{E}-05$ & 18.53 \\
\hline
\end{tabular}

Table S5: Variances and covariances, their standard error (SE), and $z$ ratio, estimated by a bivariate animal model with PHA in males and in females as two response variables.

\begin{tabular}{|ccccc|}
\hline Component & Parameter & Estimate & SE & z.ratio \\
\hline \multirow{3}{*}{ Common environment } & $\mathrm{V}_{\mathrm{f}}$ & $6.16 \mathrm{E}-03$ & $1.38 \mathrm{E}-03$ & 4.45 \\
& $\mathrm{COV}_{\mathrm{mf}}$ & $7.54 \mathrm{E}-03$ & $1.29 \mathrm{E}-03$ & 5.85 \\
& $\mathrm{~V}_{\mathrm{m}}$ & $9.88 \mathrm{E}-03$ & $1.71 \mathrm{E}-03$ & 5.77 \\
\hline \multirow{3}{*}{ Additive genetic } & $\mathrm{V}_{\mathrm{f}}$ & $7.47 \mathrm{E}-03$ & $2.15 \mathrm{E}-03$ & 3.47 \\
& $\mathrm{COV}_{\mathrm{mf}}$ & $5.71 \mathrm{E}-03$ & $1.57 \mathrm{E}-03$ & 3.64 \\
& $\mathrm{~V}_{\mathrm{m}}$ & $4.49 \mathrm{E}-03$ & $1.90 \mathrm{E}-03$ & 2.37 \\
\hline \multirow{2}{*}{ Residual } & $\mathrm{V}_{\mathrm{f}}$ & $1.15 \mathrm{E}-02$ & $1.60 \mathrm{E}-03$ & 7.22 \\
& $\mathrm{~V}_{\mathrm{m}}$ & $1.30 \mathrm{E}-02$ & $1.56 \mathrm{E}-03$ & 8.31 \\
\hline
\end{tabular}


Table S6: Variances and covariances, their standard error (SE), and $z$ ratio, estimated by a bivariate animal model with body mass in males and in females as two response variables.

\begin{tabular}{|ccccc|}
\hline Component & Parameter & Estimate & SE & z.ratio \\
\hline \multirow{3}{*}{ Common environment } & $\mathrm{V}_{\mathrm{f}}$ & 0.44 & 0.04 & 10.25 \\
& $\mathrm{COV}_{\mathrm{mf}}$ & 0.43 & 0.04 & 11.08 \\
& $\mathrm{~V}_{\mathrm{m}}$ & 0.43 & 0.04 & 10.02 \\
\hline \multirow{3}{*}{ Additive genetic } & $\mathrm{V}_{\mathrm{f}}$ & 0.24 & 0.04 & 5.69 \\
& $\mathrm{COV}_{\mathrm{mf}}$ & 0.24 & 0.04 & 6.44 \\
& $\mathrm{~V}_{\mathrm{m}}$ & 0.28 & 0.05 & 6.09 \\
\hline \multirow{2}{*}{ Residual } & $\mathrm{V}_{\mathrm{f}}$ & 0.15 & 0.03 & 5.65 \\
& $\mathrm{~V}_{\mathrm{m}}$ & 0.17 & 0.03 & 5.83 \\
\hline
\end{tabular}

Table S7: Variances and covariances, their standard error (SE), and z ratio, estimated by a bivariate animal model with wing length in males and in females as two response variables.

\begin{tabular}{|ccccc|}
\hline Component & Parameter & Estimate & SE & z.ratio \\
\hline \multirow{3}{*}{ Common environment } & $\mathrm{V}_{\mathrm{f}}$ & 4.94 & 0.50 & 9.81 \\
& $\mathrm{COV}_{\mathrm{mf}}$ & 4.79 & 0.46 & 10.47 \\
& $\mathrm{~V}_{\mathrm{m}}$ & 5.08 & 0.53 & 9.53 \\
\hline \multirow{3}{*}{ Additive genetic } & $\mathrm{V}_{\mathrm{f}}$ & 1.86 & 0.47 & 4.00 \\
& $\mathrm{COV}_{\mathrm{mf}}$ & 2.02 & 0.44 & 4.60 \\
& $\mathrm{~V}_{\mathrm{m}}$ & 2.46 & 0.61 & 4.03 \\
\hline \multirow{2}{*}{ Residual } & $\mathrm{V}_{\mathrm{f}}$ & 3.31 & 0.33 & 9.94 \\
& $\mathrm{~V}_{\mathrm{m}}$ & 3.89 & 0.43 & 8.97 \\
\hline
\end{tabular}


Figure S4: A) Additive genetic variances and their $95 \% \mathrm{Cl}$ in both sexes for all six traits and B) additive genetic covariances between these traits. These (co)variances and their uncertainties were estimated by a multivariate animal model for each sex separately.

\section{A) Variances}
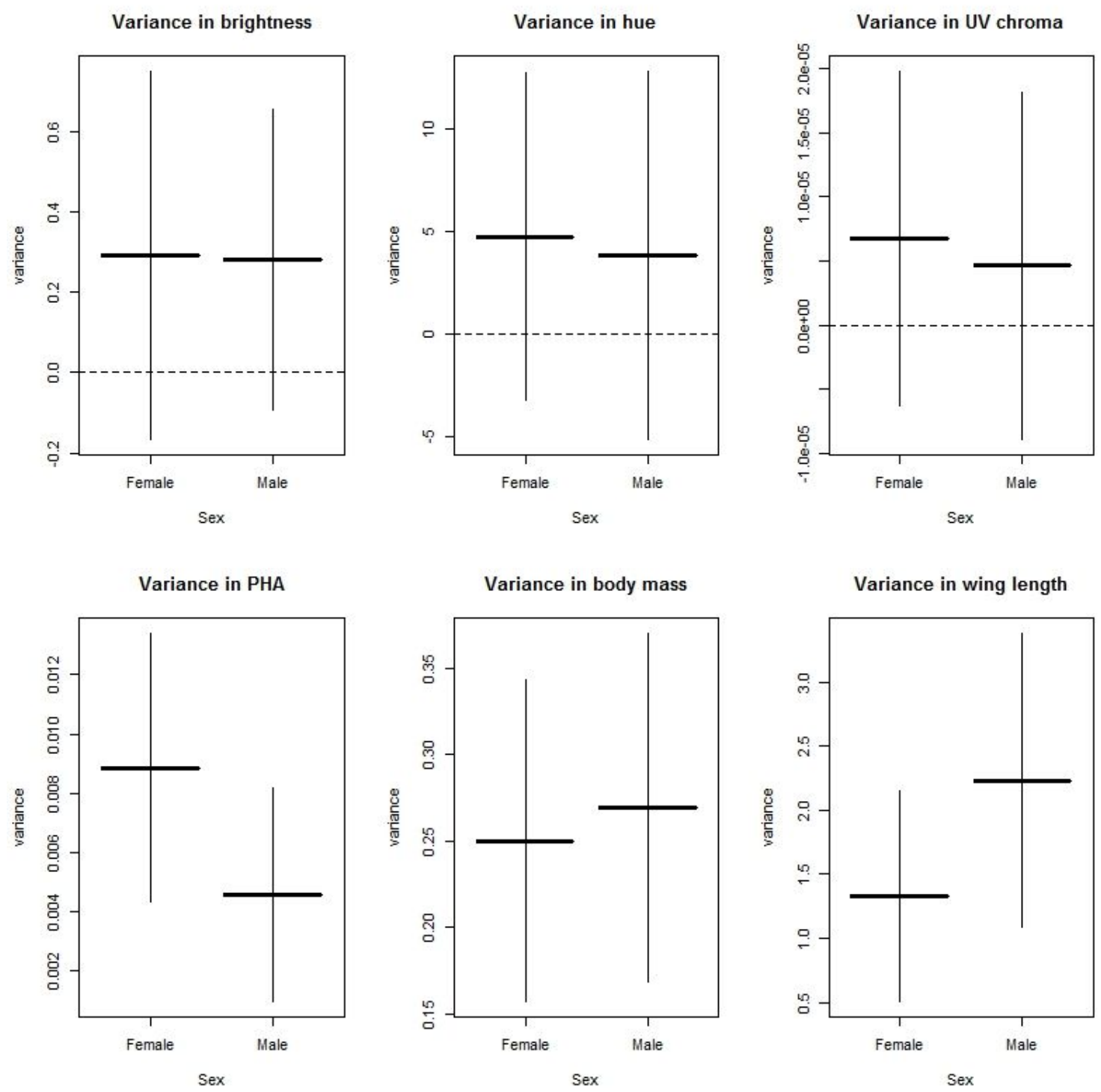


\section{B) Covariances (part 1)}
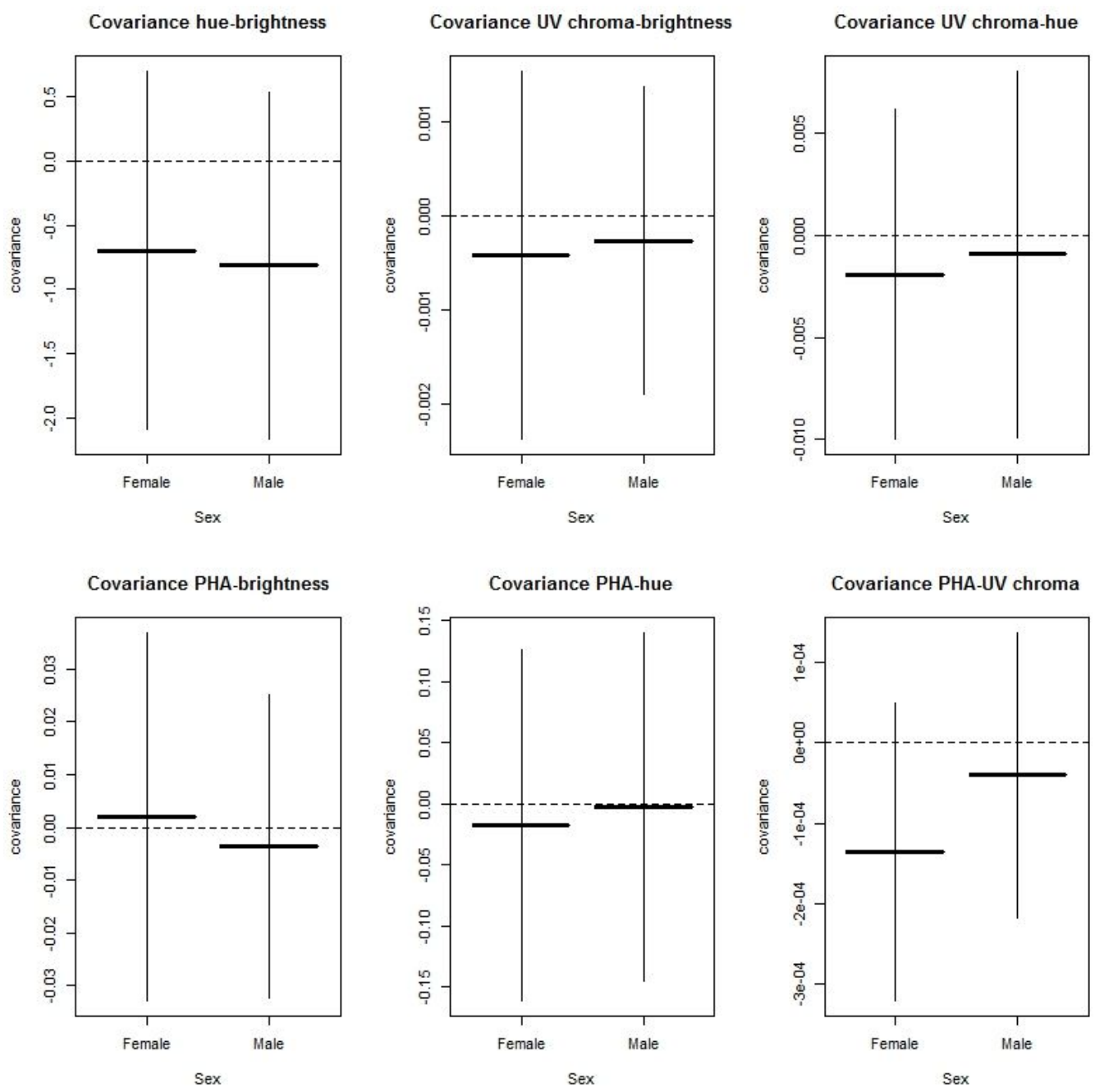
B) Covariances (part 2)
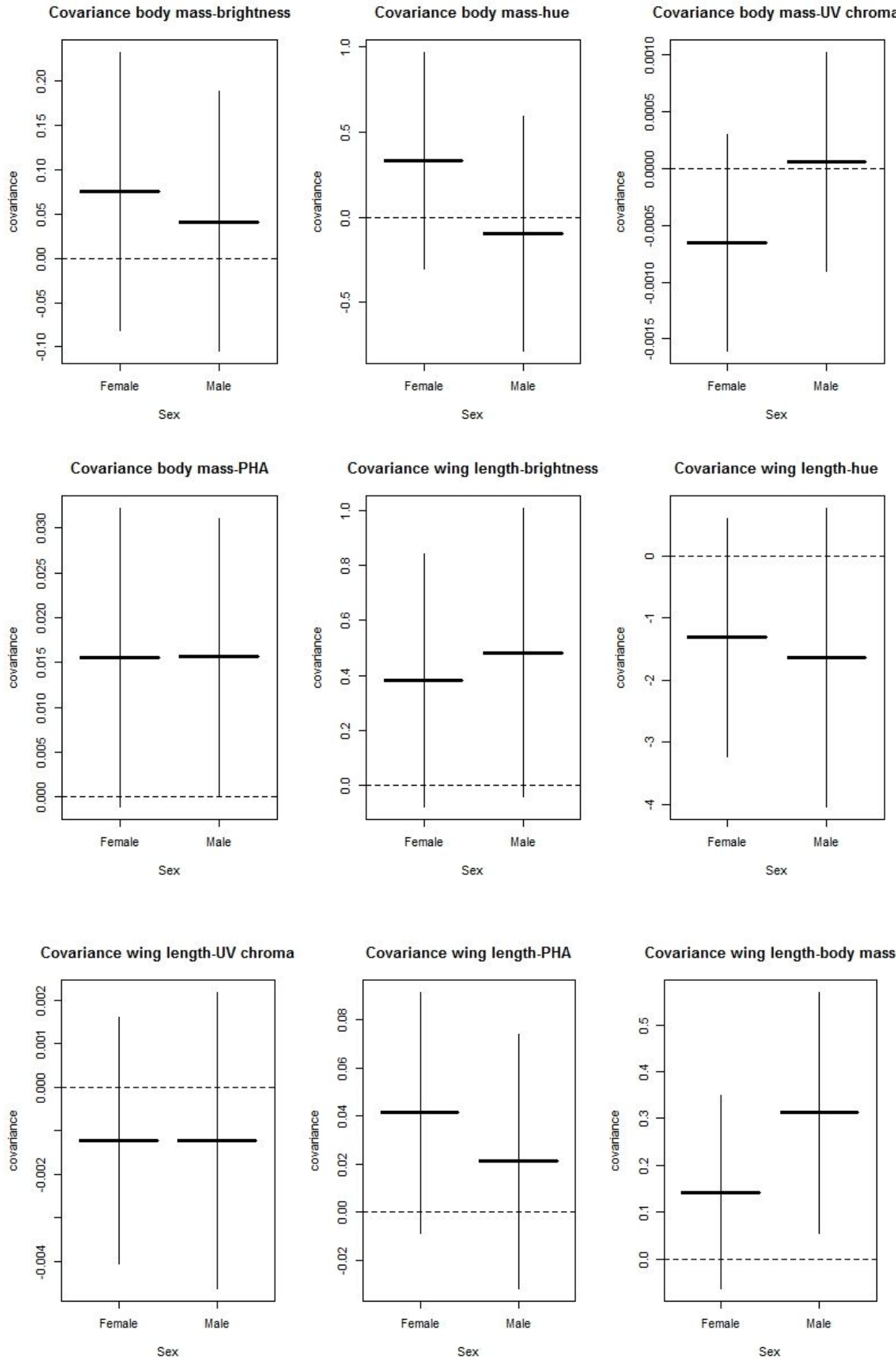
Table S8: Genetic correlation matrix estimated by a multivariate mixed model in females. In this model, fixed effects were similar to fixed effects fitted in the multivariate animal model and only the residual component was estimated. Correlations (and their standard error) are in the lower triangle and the diagonal (underlined numbers) contains phenotypic variances (and their standard error) estimated by the model. Correlations between color measures and performance traits are highlighted in grey.

\begin{tabular}{|lccccc|}
\hline Brightness & Hue & UV chroma & PHA & Body mass & Wing \\
\hline & & & & & \\
$-0.59(0.61)$ & & & & & \\
$-0.30(0.71)$ & $-0.33(0.73)$ & & & \\
$0.04(0.35)$ & $-0.09(0.36)$ & $-0.55(0.38)$ & & \\
$0.28(0.30)$ & $0.30(0.30)$ & $-0.50(0.37)$ & $0.33(0.18)$ & & \\
$0.61(0.38)$ & $-0.52(0.39)$ & $-0.40(0.48)$ & $0.38(0.24)$ & $0.25(0.18)$ & \\
\hline
\end{tabular}

Table S9: Genetic correlation matrix estimated by a multivariate mixed model in males. In this model, fixed effects were similar to fixed effects fitted in the multivariate animal model and only the residual component was estimated. Correlations (and their standard error) are in the lower triangle and the diagonal (underlined numbers) contains phenotypic variances (and their standard error) estimated by the model. Correlations between color measures and performance traits are highlighted in grey.

\begin{tabular}{|lcllll|}
\hline \multicolumn{1}{|c}{ Brightness } & Hue & UV chroma & PHA & Body mass & Wing \\
\hline & & & & & \\
$-0.79(0.67)$ & & & & \\
$-0.24(0.73)$ & $-0.22(1.09)$ & & & \\
$-0.10(0.41)$ & $-0.02(0.55)$ & $-0.28(0.62)$ & & \\
$0.15(0.27)$ & $-0.10(0.35)$ & $0.05(0.44)$ & $0.45(0.23)$ & & \\
$0.61(0.34)$ & $-0.56(0.42)$ & $-0.38(0.54)$ & $0.21(0.27)$ & $0.4(0.17)$ & \\
\hline
\end{tabular}

Table S10: Cross-sex genetic correlation and SE for each trait

\begin{tabular}{|l|l|l|}
\hline Trait & $\mathbf{R g}_{\mathbf{m f}}$ & $\mathbf{S E}$ \\
\hline Brightness & 0.99 & 0.53 \\
\hline Hue & 0.59 & 0.48 \\
\hline UV chroma & 0.95 & 0.52 \\
\hline PHA & 0.98 & 0.17 \\
\hline Body mass & 0.92 & 0.05 \\
\hline Wing length & 0.94 & 0.08 \\
\hline
\end{tabular}


Table S11: Fixed and random effects (and their standard error SE) estimated by the animal model for tail brightness. The statistical significance of additive genetic variance was tested using LRT with $1 \mathrm{df}$. The statistical significance of fixed effects was tested using conditional Wald-F tests. Coefficients of years and sex effects are reported as contrasts to year 2003 for the former and to unsexed individuals for the latter. Common environment, individual, and measurement error variances were estimated separately for each spectrophotometer (1: feathers from 2005-2006, 2: feathers from 2003, 2007-2009).

\begin{tabular}{|c|c|c|c|c|}
\hline Effect & Estimate & SE & Test statistic & p.value \\
\hline \multicolumn{5}{|l|}{ Random effects } \\
\hline Common environment 1 & 0.94 & 0.19 & & \\
\hline Common environment 2 & 1.68 & 0.21 & & \\
\hline Additive genetic & 0.26 & 0.13 & $\chi^{2}=6.19$ & 0.01 \\
\hline Individual 1 & 1.43 & 0.16 & & \\
\hline Individual 2 & 2.89 & 0.17 & & \\
\hline Measurement error 1 & 2.32 & 0.06 & & \\
\hline Measurement error 2 & 6.55 & 0.11 & & \\
\hline \multicolumn{5}{|l|}{ Fixed effects } \\
\hline Intercept & 6.85 & 0.44 & $F_{1,287.2}=842.20$ & $<0.001$ \\
\hline Vane & 0.28 & 0.02 & $F_{1,1894.0}=324.60$ & $<0.001$ \\
\hline Year & & & $F_{5,287.63}=36.18$ & $<0.001$ \\
\hline 2005 & 1.15 & 0.48 & & \\
\hline 2006 & -0.65 & 0.47 & & \\
\hline 2007 & -1.91 & 0.49 & & \\
\hline 2008 & -0.60 & 0.47 & & \\
\hline 2009 & -1.70 & 0.47 & & \\
\hline Sex & & & $F_{2,2308.1}=9.58$ & $<0.001$ \\
\hline female & 0.16 & 0.20 & & \\
\hline male & -0.18 & 0.20 & & \\
\hline
\end{tabular}


Table S12: Fixed and random effects (and their standard error SE) estimated by the animal model for tail hue. The statistical significance of additive genetic variance was tested using LRT with $1 \mathrm{df}$. The statistical significance of fixed effects was tested using conditional Wald- $F$ tests. Coefficients of years and sex effects are reported as contrasts to year 2003 for the former and to unsexed individuals for the latter. Common environment, individual, and measurement error variances were estimated separately for each spectrophotometer (1: feathers from 2005-2006, 2: feathers from 2003, 20072009).

\begin{tabular}{|c|c|c|c|c|}
\hline Effect & Estimate & SE & Test statistic & p.value \\
\hline \multicolumn{5}{|l|}{ Random effects } \\
\hline Common environment 1 & 11.39 & 2.52 & & \\
\hline Common environment 2 & 24.11 & 3.06 & & \\
\hline Additive genetic & 1.20 & 2.02 & $\chi^{2}=0.20$ & 0.65 \\
\hline Individual 1 & 19.66 & 2.76 & & \\
\hline Individual 2 & 40.32 & 2.75 & & \\
\hline Measurement error 1 & 82.47 & 2.12 & & \\
\hline Measurement error 2 & 122.60 & 2.06 & & \\
\hline \multicolumn{5}{|l|}{ Fixed effects } \\
\hline Intercept & 354.16 & 1.68 & $F_{1,219.7}=1.89 E+05$ & $<0.001$ \\
\hline Vane & -0.44 & 0.06 & $F_{1,1629.8}=52.1$ & $<0.001$ \\
\hline Year & & & $F_{5,283.7}=24.09$ & $<0.001$ \\
\hline 2005 & -4.93 & 1.82 & & \\
\hline 2006 & -10.89 & 1.79 & & \\
\hline 2007 & -10.28 & 1.85 & & \\
\hline 2008 & -9.79 & 1.79 & & \\
\hline 2009 & -4.65 & 1.79 & & \\
\hline Sex & & & $F_{2,2387.1}=5.98$ & 0.002 \\
\hline female & -0.42 & 0.79 & & \\
\hline male & -1.43 & 0.78 & & \\
\hline
\end{tabular}


Table S13: Fixed and random effects (and their standard error SE) estimated by the animal model for tail UV chroma. The statistical significance of additive genetic variance was tested using LRT with $1 \mathrm{df}$. The statistical significance of fixed effects was tested using conditional Wald-F tests. Coefficients of years and sex effects are reported as contrasts to year 2003 for the former and to unsexed individuals for the latter. Common environment, individual, and measurement error variances were estimated separately for each spectrophotometer (1: feathers from 2005-2006, 2: feathers from 2003, 2007-2009).

\begin{tabular}{|c|c|c|c|c|}
\hline Effect & Estimate & SE & Test statistic & p.value \\
\hline \multicolumn{5}{|l|}{ Random effects } \\
\hline Common environment 1 & $1.63 \mathrm{E}-05$ & $3.54 \mathrm{E}-06$ & & \\
\hline Common environment 2 & $1.35 \mathrm{E}-04$ & $1.78 \mathrm{E}-05$ & & \\
\hline Additive genetic & $6.24 \mathrm{E}-06$ & 3.93E-06 & $\chi^{2}=4.31$ & 0.04 \\
\hline Individual 1 & $2.84 \mathrm{E}-05$ & 3.79E-06 & & \\
\hline Individual 2 & $3.32 \mathrm{E}-04$ & $1.58 \mathrm{E}-05$ & & \\
\hline Measurement error 1 & 4.83E-05 & $1.24 \mathrm{E}-06$ & & \\
\hline Measurement error 2 & 5.51E-04 & $9.25 \mathrm{E}-06$ & & \\
\hline \multicolumn{5}{|l|}{ Fixed effects } \\
\hline Intercept & $3.32 \mathrm{E}-01$ & $3.85 \mathrm{E}-03$ & $F_{1,149.6}=72020.00$ & $<0.001$ \\
\hline Vane & $-3.58 \mathrm{E}-04$ & 8.97E-05 & $F_{1,779.1}=15.92$ & $<0.001$ \\
\hline Year & & & $F_{5,295.7}=66.67$ & $<0.001$ \\
\hline 2005 & $-1.74 \mathrm{E}-02$ & $3.95 \mathrm{E}-03$ & & \\
\hline 2006 & $-1.30 \mathrm{E}-02$ & $3.93 \mathrm{E}-03$ & & \\
\hline 2007 & $9.45 \mathrm{E}-03$ & 4.29E-03 & & \\
\hline 2008 & $1.79 \mathrm{E}-03$ & 4.14E-03 & & \\
\hline 2009 & $6.58 \mathrm{E}-05$ & 4.10E-03 & & \\
\hline Sex & & & $F_{2,1083.4}=157.10$ & $<0.001$ \\
\hline female & $-1.93 \mathrm{E}-03$ & $1.20 \mathrm{E}-03$ & & \\
\hline male & $6.10 \mathrm{E}-03$ & 1.19E-03 & & \\
\hline
\end{tabular}


Table S14: Fixed and random effects (and their standard error SE) estimated by the animal model for PHA response. The statistical significance of random effects was tested using LRT with $1 \mathrm{df}$. The statistical significance of fixed effects was tested using conditional Wald- $F$ tests. Coefficients of years and sex effects are reported as contrasts to year 2003 for the former and to unsexed individuals for the latter.

\begin{tabular}{|c|c|c|c|c|}
\hline Effect & Estimate & SE & Test statistic & p.value \\
\hline \multicolumn{5}{|l|}{ Random effects } \\
\hline Common environment & 7.83E-03 & $1.21 \mathrm{E}-03$ & $\chi^{2}=153.09$ & $<0.001$ \\
\hline Additive genetic & 5.17E-03 & $1.36 \mathrm{E}-03$ & $\chi^{2}=46.48$ & $<0.001$ \\
\hline Residual & $1.30 \mathrm{E}-02$ & $1.02 \mathrm{E}-03$ & & \\
\hline \multicolumn{5}{|l|}{ Fixed effects } \\
\hline Intercept & 0.49 & 0.03 & $F_{1,196.7}=3920.0$ & $<0.001$ \\
\hline \multirow[t]{4}{*}{ Year } & & & $F_{3,207.9}=6.52$ & $<0.001$ \\
\hline & 0.04 & 0.04 & & \\
\hline & 0.06 & 0.04 & & \\
\hline & -0.02 & 0.04 & & \\
\hline \multirow[t]{3}{*}{ Sex } & & & $\mathrm{F}_{1,1422.8}=1.69$ & 0.85 \\
\hline & 0.035 & 0.02 & & \\
\hline & 0.037 & 0.02 & & \\
\hline
\end{tabular}


Table S15: Fixed and random effects (and their standard error SE) estimated by the animal model for body mass. The statistical significance of random effects was tested using LRT with $1 \mathrm{df}$. The statistical significance of fixed effects was tested using conditional Wald- $F$ tests. Coefficients of years and sex effects are reported as contrasts to year 2003 for the former and to unsexed individuals for the latter.

\begin{tabular}{|c|c|c|c|c|}
\hline Effect & Estimate & SE & Test statistic & p.value \\
\hline \multicolumn{5}{|l|}{ Random effects } \\
\hline Common environment & 0.49 & 0.04 & $\chi^{2}=1093.62$ & $<0.001$ \\
\hline Additive genetic & 0.25 & 0.04 & $\chi^{2}=185.67$ & $<0.001$ \\
\hline Residual & 0.19 & 0.02 & & \\
\hline \multicolumn{5}{|l|}{ Fixed effects } \\
\hline Intercept & 8.51 & 0.27 & $F_{1,494.3}=2401.00$ & $<0.001$ \\
\hline Tarsus & 0.13 & 0.01 & $F_{1,3107.0}=184.50$ & $<0.001$ \\
\hline \multirow[t]{6}{*}{ Year } & & & $F_{5,404.4}=12.95$ & $<0.001$ \\
\hline & 0.42 & 0.24 & & \\
\hline & 0.68 & 0.24 & & \\
\hline & 0.17 & 0.23 & & \\
\hline & 0.85 & 0.23 & & \\
\hline & 0.92 & 0.22 & & \\
\hline Sex & & & $F_{1,2928.2}=213.00$ & $<0.001$ \\
\hline female & -0.27 & 0.06 & & \\
\hline male & 0.21 & 0.06 & & \\
\hline
\end{tabular}


Table S16: Fixed and random effects (and their standard error SE) estimated by the animal model for wing length. The statistical significance of random effects was tested using LRT with $1 \mathrm{df}$. The statistical significance of fixed effects was tested using conditional Wald- $F$ tests. Coefficients of years and sex effects are reported as contrasts to year 2003 for the former and to unsexed individuals for the latter.

\begin{tabular}{|c|c|c|c|c|}
\hline Effect & Estimate & SE & Test statistic & p.value \\
\hline \multicolumn{5}{|l|}{ Random effects } \\
\hline Common environment & 4.87 & 0.46 & $\chi^{2}=616.89$ & $<0.001$ \\
\hline Additive genetic & 3.26 & 0.57 & $\chi^{2}=64.74$ & $<0.001$ \\
\hline Residual & 3.46 & 0.35 & & \\
\hline \multicolumn{5}{|l|}{ Fixed effects } \\
\hline Intercept & 44.56 & 0.69 & $F_{1,435.6}=97880.00$ & $<0.001$ \\
\hline \multirow[t]{6}{*}{ Year } & & & $F_{5,404.0}=7.34$ & $<0.001$ \\
\hline & 1.31 & 0.82 & & \\
\hline & 2.85 & 0.80 & & \\
\hline & 0.44 & 0.77 & & \\
\hline & 1.43 & 0.77 & & \\
\hline & 0.84 & 0.76 & & \\
\hline Sex & & & $F_{1,2953.4}=25.18$ & $<0.001$ \\
\hline female & 0.09 & 0.25 & & \\
\hline male & 0.72 & 0.25 & & \\
\hline
\end{tabular}


Table S17: Variances of wing web thickness measured on day 13 and day 14 and their covariances estimated on different levels by a bivariate animal model (and their standard errors (SE)).In this model, year and sex were fitted as fixed effects for each response separately and random effects included common environment effects, individual identity, additive genetic effects and measurement error. Measurement error covariance was not fitted as both measures were not taken at the same time. Variance of the PHA response on each level can then be estimated as the sum of both variances minus twice their covariance and heritability is calculated as VA/VP where VP does not include measurement error.

\begin{tabular}{|lcc|}
\hline (Co)Variance component & Estimate & SE \\
\hline Common environment: WingWeb_d13 & 3.89 & 0.51 \\
Common environment:WingWeb_d14:WingWeb_d13 & 7.28 & 1.25 \\
Common environment: WingWeb_d14 & 33.77 & 4.87 \\
Additive genetic: WingWeb_d13 & 0.52 & 0.23 \\
Additive genetic: WingWeb_d14:WingWeb_d13 & -1.16 & 0.64 \\
Additive genetic: WingWeb_d14 & 11.97 & 3.62 \\
Individual: WingWeb_d13 & 3.89 & 0.23 \\
Individual: WingWeb_d14:WingWeb_d13 & 2.29 & 0.61 \\
Individual: WingWeb_d14 & 55.62 & 3.28 \\
Measurement error: WingWeb_d13 & 0.71 & 0.03 \\
Measurement error: WingWeb_d14 & 3.24 & 0.08 \\
\hline Common environment: PHA & 23.10 & 3.77 \\
Additive genetic: PHA & 14.82 & 3.98 \\
Individual: PHA & 54.94 & 3.41 \\
\hline
\end{tabular}


Table S18: Additive genetic covariance matrix derived from the multivariate animal model. The diagonal contains additive genetic variances and standard errors are printed below each estimate in grey. Covariances between color measures and performance traits are highlighted in yellow.

\begin{tabular}{|c|c|c|c|c|c|c|}
\hline & Brightness & Hue & UV chroma & PHA & Body mass & Wing \\
\hline Brightness & $\begin{array}{l}0.28 \\
0.12\end{array}$ & & & & & \\
\hline Hue & $\begin{array}{l}-0.80 \\
0.44\end{array}$ & $\begin{array}{l}4.44 \\
2.90\end{array}$ & & & & \\
\hline UV chroma & $\begin{array}{c}-1.60 \mathrm{E}-04 \\
4.93 \mathrm{E}-04\end{array}$ & $\begin{array}{c}-1.63 \mathrm{E}-03 \\
2.59 \mathrm{E}-03\end{array}$ & $\begin{array}{c}5.19 \mathrm{E}-06 \\
3.58 \mathrm{E}-06\end{array}$ & & & \\
\hline PHA & $\begin{array}{c}-1.87 \mathrm{E}-03 \\
9.72 \mathrm{E}-03\end{array}$ & $\begin{array}{c}-0.01 \\
0.05\end{array}$ & $\begin{array}{c}-8.30 \mathrm{E}-05 \\
5.47 \mathrm{E}-05\end{array}$ & $\begin{array}{c}5.32 \mathrm{E}-03 \\
1.31 \mathrm{E}-03\end{array}$ & & \\
\hline Body mass & $\begin{array}{l}0.05 \\
0.05\end{array}$ & $\begin{array}{l}0.13 \\
0.23\end{array}$ & $\begin{array}{c}-1.86 \mathrm{E}-04 \\
3.04 \mathrm{E}-04\end{array}$ & $\begin{array}{c}8.15 \mathrm{E}-03 \\
5.46 \mathrm{E}-03\end{array}$ & $\begin{array}{l}0.23 \\
0.03\end{array}$ & \\
\hline Wing & $\begin{array}{l}0.34 \\
0.17\end{array}$ & $\begin{array}{l}-1.42 \\
0.78\end{array}$ & $\begin{array}{c}-1.01 \mathrm{E}-03 \\
1.04 \mathrm{E}-03\end{array}$ & $\begin{array}{c}3.05 \mathrm{E}-02 \\
1.81 \mathrm{E}-02\end{array}$ & $\begin{array}{l}0.16 \\
0.08\end{array}$ & $\begin{array}{l}1.73 \\
0.37\end{array}$ \\
\hline
\end{tabular}


Table S19: First common environment (CE1) covariance matrix derived from the multivariate animal model. The diagonal contains CE1 variances and standard errors are printed below each estimate in grey. Covariances between color measures and performance traits are highlighted in yellow.

\begin{tabular}{|c|c|c|c|c|c|c|}
\hline & Brightness & Hue & UV chroma & PHA & Body mass & Wing \\
\hline Brightness & $\begin{array}{l}1.04 \\
0.21\end{array}$ & & & & & \\
\hline Hue & $\begin{array}{c}-0.42 \\
0.57\end{array}$ & $\begin{array}{c}12.93 \\
3.00\end{array}$ & & & & \\
\hline UV chroma & $\begin{array}{c}-1.50 \mathrm{E}-03 \\
6.52 \mathrm{E}-04\end{array}$ & $\begin{array}{c}-4.17 \mathrm{E}-03 \\
2.43 \mathrm{E}-03\end{array}$ & $\begin{array}{c}1.74 \mathrm{E}-05 \\
3.69 \mathrm{E}-06\end{array}$ & & & \\
\hline PHA & $\begin{array}{l}0.04 \\
0.02\end{array}$ & $\begin{array}{l}-0.01 \\
0.06\end{array}$ & $\begin{array}{c}7.64 \mathrm{E}-05 \\
6.53 \mathrm{E}-05\end{array}$ & $\begin{array}{l}1.12 \mathrm{E}-02 \\
2.18 \mathrm{E}-03\end{array}$ & & \\
\hline Body mass & $\begin{array}{l}0.34 \\
0.11\end{array}$ & $\begin{array}{l}0.31 \\
0.41\end{array}$ & $\begin{array}{c}9.01 \mathrm{E}-04 \\
4.58 \mathrm{E}-04\end{array}$ & $\begin{array}{c}5.25 \mathrm{E}-02 \\
0.01\end{array}$ & $\begin{array}{l}0.60 \\
0.10\end{array}$ & \\
\hline Wing & $\begin{array}{l}1.50 \\
0.43\end{array}$ & $\begin{array}{l}1.21 \\
1.53\end{array}$ & $\begin{array}{c}1.80 \mathrm{E}-04 \\
1.70 \mathrm{E}-03\end{array}$ & $\begin{array}{c}1.41 \mathrm{E}-01 \\
0.04\end{array}$ & $\begin{array}{l}1.18 \\
0.30\end{array}$ & $\begin{array}{l}7.92 \\
1.40\end{array}$ \\
\hline
\end{tabular}

Table S20: Second common environment (CE2) covariance matrix derived from the multivariate animal model. The diagonal contains CE1 variances and standard errors are printed below each estimate in grey. Covariances between color measures and performance traits are highlighted in yellow.

\begin{tabular}{|c|c|c|c|c|c|c|}
\hline & Brightness & Hue & UV chroma & PHA & Mass & Wing \\
\hline Brightness & $\begin{array}{l}1.95 \\
0.24\end{array}$ & & & & & \\
\hline Hue & $\begin{array}{c}-1.52 \\
0.65\end{array}$ & $\begin{array}{c}25.09 \\
3.43\end{array}$ & & & & \\
\hline UV chroma & $\begin{array}{c}-1.16 \mathrm{E}-02 \\
1.77 \mathrm{E}-03\end{array}$ & $\begin{array}{c}-1.74 \mathrm{E}-02 \\
5.91 \mathrm{E}-03\end{array}$ & $\begin{array}{c}1.44 \mathrm{E}-04 \\
1.84 \mathrm{E}-05\end{array}$ & & & \\
\hline PHA & $\begin{array}{l}0.01 \\
0.02\end{array}$ & $\begin{array}{c}3.43 \mathrm{E}-03 \\
5.84 \mathrm{E}-02\end{array}$ & $\begin{array}{c}-1.01 \mathrm{E}-04 \\
1.30 \mathrm{E}-04\end{array}$ & $\begin{array}{c}3.45 \mathrm{E}-03 \\
9.62 \mathrm{E}-04\end{array}$ & & \\
\hline Mass & $\begin{array}{l}0.32 \\
0.08\end{array}$ & $\begin{array}{c}-0.09 \\
0.29\end{array}$ & $\begin{array}{c}-2.20 \mathrm{E}-03 \\
6.70 \mathrm{E}-04\end{array}$ & $\begin{array}{c}1.89 \mathrm{E}-02 \\
6.11 \mathrm{E}-03\end{array}$ & $\begin{array}{l}0.46 \\
0.05\end{array}$ & \\
\hline Wing & $\begin{array}{l}1.51 \\
0.25\end{array}$ & $\begin{array}{c}-2.00 \\
0.90\end{array}$ & $\begin{array}{c}-7.99 \mathrm{E}-03 \\
2.09 \mathrm{E}-03\end{array}$ & $\begin{array}{c}3.65 \mathrm{E}-03 \\
2.00 \mathrm{E}-02\end{array}$ & $\begin{array}{l}0.67 \\
0.11\end{array}$ & $\begin{array}{l}4.18 \\
0.44\end{array}$ \\
\hline
\end{tabular}


Table S21: First residual (RES1) covariance matrix derived from the multivariate animal model. The diagonal contains RES1 variances and standard errors are printed below each estimate in grey. Covariances between color measures and performance traits are highlighted in yellow.

\begin{tabular}{|c|c|c|c|c|c|c|}
\hline & Brightness & Hue & UV chroma & PHA & Body mass & Wing \\
\hline Brightness & $\begin{array}{l}2.02 \\
0.16\end{array}$ & & & & & \\
\hline Hue & $\begin{array}{c}-0.02 \\
0.54\end{array}$ & $\begin{array}{c}45.29 \\
3.61\end{array}$ & & & & \\
\hline UV chroma & $\begin{array}{c}-1.75 \mathrm{E}-03 \\
5.50 \mathrm{E}-04\end{array}$ & $\begin{array}{c}-1.01 \mathrm{E}-02 \\
2.81 \mathrm{E}-03\end{array}$ & $\begin{array}{c}4.08 \mathrm{E}-05 \\
3.73 \mathrm{E}-06\end{array}$ & & & \\
\hline PHA & $\begin{array}{c}-3.96 \mathrm{E}-03 \\
1.07 \mathrm{E}-02\end{array}$ & $\begin{array}{l}0.03 \\
0.05\end{array}$ & $\begin{array}{c}1.02 \mathrm{E}-04 \\
5.30 \mathrm{E}-05\end{array}$ & $\begin{array}{c}1.44 \mathrm{E}-02 \\
1.28 \mathrm{E}-03\end{array}$ & & \\
\hline Body mass & $\begin{array}{l}0.01 \\
0.05\end{array}$ & $\begin{array}{l}-0.19 \\
0.26\end{array}$ & $\begin{array}{c}6.53 \mathrm{E}-04 \\
2.75 \mathrm{E}-04\end{array}$ & $\begin{array}{c}1.51 \mathrm{E}-02 \\
4.84 \mathrm{E}-03\end{array}$ & $\begin{array}{l}0.27 \\
0.03\end{array}$ & \\
\hline Wing & $\begin{array}{l}0.41 \\
0.22\end{array}$ & $\begin{array}{l}1.53 \\
1.06\end{array}$ & $\begin{array}{c}3.81 \mathrm{E}-03 \\
1.14 \mathrm{E}-03\end{array}$ & $\begin{array}{l}0.05 \\
0.02\end{array}$ & $\begin{array}{l}0.72 \\
0.10\end{array}$ & $\begin{array}{l}7.78 \\
0.54\end{array}$ \\
\hline
\end{tabular}

Table S22: Second residual (RES2) covariance matrix derived from the multivariate animal model. The diagonal contains RES2 variances and standard errors are printed below each estimate in grey. Covariances between color measures and performance traits are highlighted in yellow.

\begin{tabular}{|c|c|c|c|c|c|c|}
\hline & Brightness & Hue & UV chroma & PHA & Body mass & Wing \\
\hline Brightness & $\begin{array}{l}4.68 \\
0.18\end{array}$ & & & & & \\
\hline Hue & $\begin{array}{l}0.82 \\
0.55\end{array}$ & $\begin{array}{c}84.91 \\
3.39\end{array}$ & & & & \\
\hline UV chroma & $\begin{array}{c}-2.98 \mathrm{E}-02 \\
1.34 \mathrm{E}-03\end{array}$ & $\begin{array}{c}-0.08 \\
0.01\end{array}$ & $\begin{array}{c}4.61 \mathrm{E}-04 \\
1.55 \mathrm{E}-05\end{array}$ & & & \\
\hline PHA & $\begin{array}{c}8.84 \mathrm{E}-03 \\
1.51 \mathrm{E}-02\end{array}$ & $\begin{array}{c}-0.05 \\
0.06\end{array}$ & $\begin{array}{c}7.23 \mathrm{E}-05 \\
1.26 \mathrm{E}-04\end{array}$ & $\begin{array}{c}1.14 \mathrm{E}-02 \\
1.06 \mathrm{E}-03\end{array}$ & & \\
\hline Body mass & $\begin{array}{l}0.06 \\
0.04\end{array}$ & $\begin{array}{c}-0.50 \\
0.18\end{array}$ & $\begin{array}{c}-3.15 \mathrm{E}-04 \\
3.30 \mathrm{E}-04\end{array}$ & $\begin{array}{c}5.99 \mathrm{E}-03 \\
3.77 \mathrm{E}-03\end{array}$ & $\begin{array}{l}0.19 \\
0.02\end{array}$ & \\
\hline Wing & $\begin{array}{l}0.95 \\
0.15\end{array}$ & $\begin{array}{c}-1.54 \\
0.64\end{array}$ & $\begin{array}{c}-7.07 \mathrm{E}-03 \\
1.22 \mathrm{E}-03\end{array}$ & $\begin{array}{c}7.42 \mathrm{E}-03 \\
1.39 \mathrm{E}-02\end{array}$ & $\begin{array}{l}0.33 \\
0.05\end{array}$ & $\begin{array}{l}3.35 \\
0.24\end{array}$ \\
\hline
\end{tabular}


Table S23: Phenotypic correlation matrix estimated by a multivariate mixed model. In this model, fixed effects were similar to fixed effects fitted in the multivariate animal model and only the residual component was estimated. Correlations (and their standard error) are in the lower triangle and the diagonal (underlined numbers) contains phenotypic variances (and their standard error) estimated by the model. Correlations between color measures and performance traits are highlighted in grey.

\begin{tabular}{|c|c|c|c|c|c|c|}
\hline & Brightness & Hue & UV chroma & PHA & Body mass & Wing \\
\hline Brightness & $5.85(0.15)$ & & & & & \\
\hline Hue & $-0.06(0.02)$ & $\underline{99.5(2.64)}$ & & & & \\
\hline $\begin{array}{c}\text { UV } \\
\text { chroma }\end{array}$ & $-0.59(0.01)$ & $-0.36(0.02)$ & $4.5 \mathrm{E}-04(1.20 \mathrm{E}-05)$ & & & \\
\hline PHA & $0.07(0.03)$ & $-0.05(0.03)$ & $-0.01(0.03)$ & $\underline{2.55 E-02(9.18 E-04)}$ & & \\
\hline Body & & & & & & \\
\hline mass & $0.19(0.02)$ & $-0.06(0.02)$ & $-0.07(0.02)$ & $0.33(0.02)$ & $\underline{0.90(0.02)}$ & \\
\hline Wing & $0.32(0.02)$ & $-0.13(0.02)$ & $-0.12(0.02)$ & $0.21(0.02)$ & $0.41(0.01)$ & $10.71(0.27)$ \\
\hline
\end{tabular}


Figure S5: Correlations (solid arrows) and loadings (dashed arrows) estimated in the structural equation models.
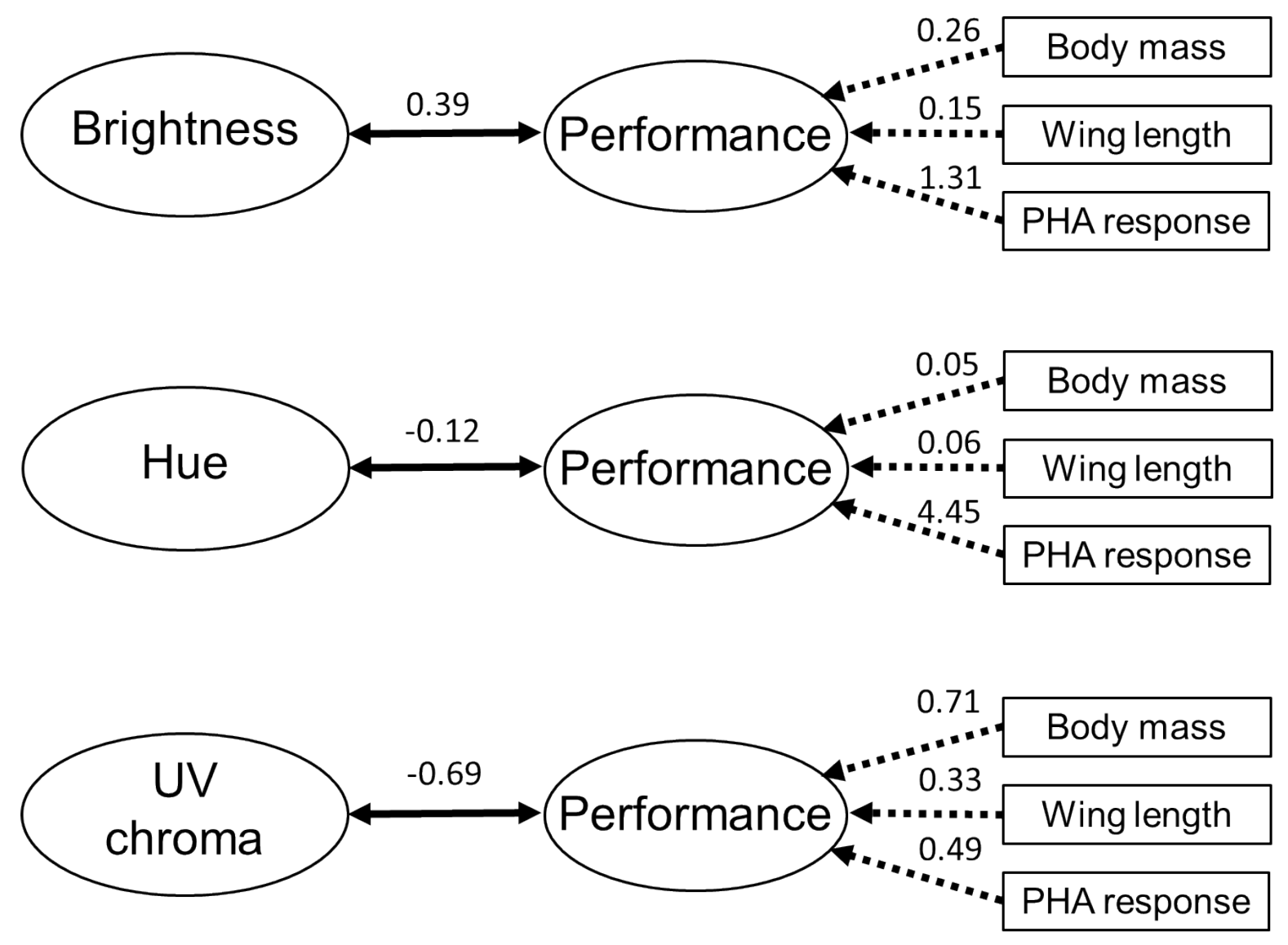


\section{Text S1: $R$ code for performing the quantitative genetic analyses}

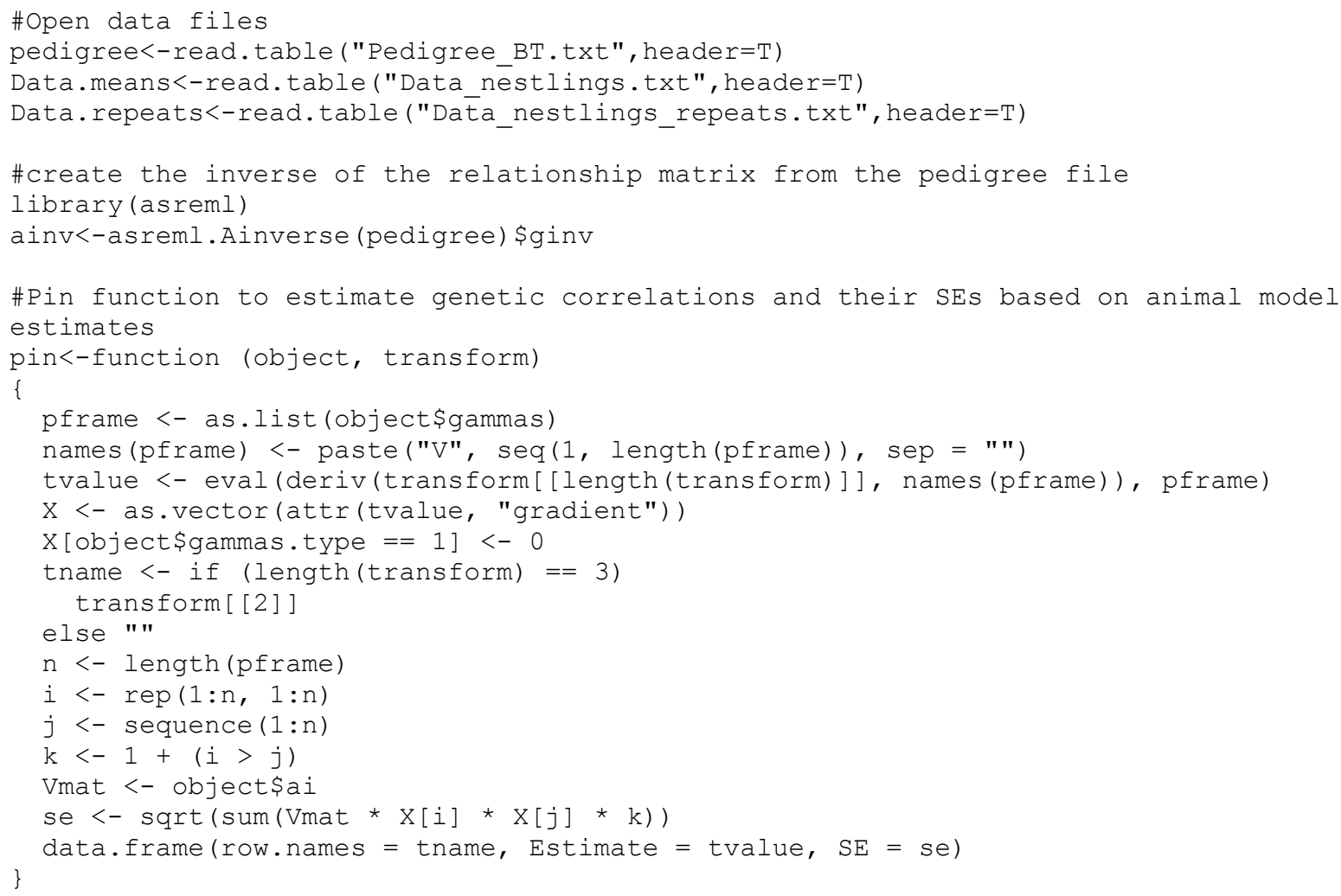

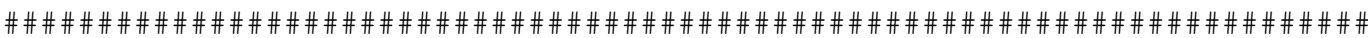
\#Estimate heritability of nestling color traits (using repeated measures)

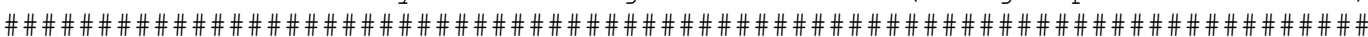

\#Prepare data for the models

Data.repeats $\$$ Ring $<-$ as. factor (Data.repeats\$Ring)

Data.repeats \$NestID<-as.factor (Data.repeats \$NestID)

Data.repeats $\$$ GeneticID<-as.factor (Data.repeats \$GeneticID)

Data.repeats\$Year<-as.factor (Data.repeats\$Year)

Data.repeats $\$$ Sex<-as. factor (Data.repeats $\$$ Sex)

Data.repeats \$machine<-as. factor (Data.repeats\$machine)

Data.repeats $<-$ droplevels (Data.repeats) 
\#I) Brightness modelbria<-asreml (fixed=brightness n $1+$ Sex +Vane + Year

, random $=\sim \operatorname{ped}(\mathrm{R} \overline{\mathrm{i}} \mathrm{n})$ + at (machine) $:$ ide (Ring) +at (machine) : NestID

, rcov $=\sim$ at (machine) : units

, data=Data.repeats

, ginverse=list (Ring=ainv)

, na.method.X="include", na.method.Y="omit")

summary (modelbria) \$varcomp

wald.asreml (modelbria,ssType = "conditional", denDF="numeric")\#Test significance of fixed effects

modelbria\$coefficients\$fixed\#Coefficients of fixed effects

pin2 (modelbria, h2 V3/(V1+V3+V4)) \#First h2

pin2 (modelbria, h2 V3/(V2+V3+V5)) \#Second h2

pin2 (modelbria, CE2 V1/(V1+V3+V4)) \#First VCE/VP

pin2 (modelbria, $\mathrm{CE} 2 \sim \mathrm{V} 2 /(\mathrm{V} 2+\mathrm{V} 3+\mathrm{V} 5)$ ) \# Second $\mathrm{VCE} / \mathrm{VP}$

modelbrib<-asreml (fixed=brightness $\mathrm{n} \sim 1$ + Sex +Vane + Year

, random= at (machine): ide (Ring) +at (machine) : NestID

, $r \mathrm{cov}=\sim$ at (machine) : units

, data=Data.repeats

, ginverse=list (Ring=ainv)

, na.method.X="include", na.method.Y="omit")

1-pchisq (2* (modelbria\$loglik-modelbrib\$loglik), 1)\#Test if VA in brightness is significantly different from zero

\#II) Hue

modelhuea<-asreml (fixed=hue_n $1+$ Sex +Vane + Year

, random $=-\sim$ ped (Ring) + at (machine) :ide (Ring) +at (machine) : NestID

, $r \mathrm{cov}=\sim$ at (machine) : units

, data=Data.repeats

, ginverse=list (Ring=ainv)

, na.method.X="include", na.method.Y="omit", maxiter=100)

summary (modelhuea) \$varcomp

wald.asreml (modelhuea, ssType = "conditional", denDF="numeric")\#Test significance of fixed effects

modelhuea\$coefficients\$fixed\#Coefficients of fixed effects

pin2 (modelhuea, h2 V3/(V1+V3+V4)) \#First h2

pin2 (modelhuea, h2 V3/(V2+V3+V5)) \#Second h2

pin2 (modelhuea, CE2 V1/(V1+V3+V4)) \#First VCE/VP

pin2 (modelhuea, CE2 V2/(V2+V3+V5)) \#Second VCE/VP

modelhueb<-asreml (fixed=hue_n $1+$ Sex +Vane + Year

, random $=\sim$ at (machine) : ide(Ring) tat (machine) : NestID

, rcov $=\sim$ at (machine) : units

, data=Data.repeats

, ginverse=list (Ring=ainv)

summary (modelhueb)

, na.method.X="include", na.method.Y="omit")

1 -pchisq (2*(modelhuea\$loglik-modelhueb\$loglik), 1)\#Test if VA in hue is

significantly different from zero

\#III) UV chroma

modelUVa<-asreml (fixed=UV. chrome_n 1 + Sex +Vane + Year

, random $=\sim \operatorname{ped}(\overline{\mathrm{R}} \mathrm{ng})+$ at (machine) : ide (Ring) +at (machine) : NestID

, rcov $=\sim$ at (machine) : units

, data=Data.repeats

, ginverse=list (Ring=ainv)

, na.method.X="include", na.method.Y="omit")

summary (modelUVa) \$varcomp 
wald.asreml (modelUVa, ssType = "conditional", denDF="numeric")\#Test significance of fixed effects

modelUVa\$coefficients\$fixed\#Coefficients of fixed effects

pin2 (modeluVa, h2 V3/(V1+V3+V4)) \#First h2

pin2 (modelUVa, h2 V3/(V2+V3+V5)) \#Second h2

pin2 (modeluVa, CE2 V1/(V1+V3+V4)) \#First VCE/VP

pin2 (modeluVa, CE2 V2/(V2+V3+V5)) \#Second VCE/VP

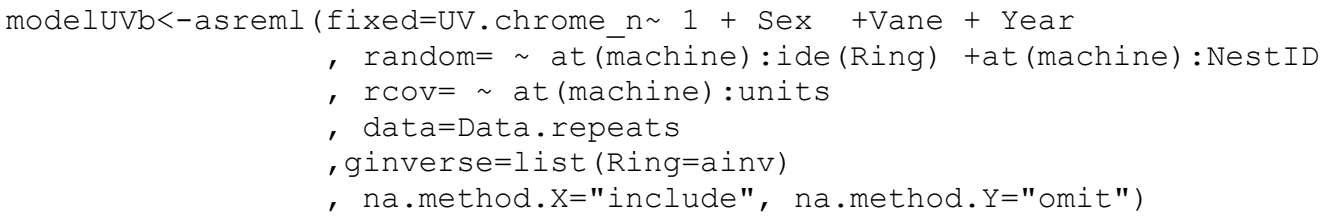

1-pchisq $(2 *$ (modelUVa\$loglik-modelUVb\$loglik),1)\#Test if VA in UV chroma is significantly different from zero

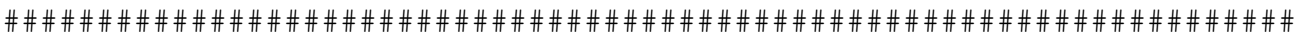

\#Estimate heritability of nestling traits (using individual averages)

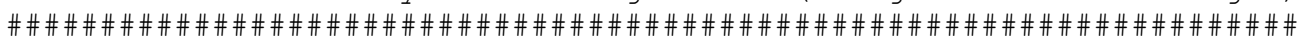

\#Prepare data for the models

Data.means $\$$ Nest ID<-as. factor (Data.means $\$$ NestID)

Data.means\$GeneticID<-as.factor (Data.means\$GeneticID)

Data.means $\$$ Year $<-a s$. factor (Data.means\$Year)

Data.means \$machine<-as. factor (Data.means \$machine)

Data.means\$Ring<-as. factor (Data.means\$Ring)

Data.means\$Sex<-as.factor (Data.means\$Sex)

\# I) Brightness

modelbri<-asreml (fixed=brightness_n 1 + Sex +Vane + Year

, random= ped (Ring) tat (machine) $:$ NestID

, rcov $=\sim$ at (machine) : units

, data=Data.means

, ginverse=list (Ring=ainv)

, na.method.X="include", na.method.Y="omit")

summary (modelbri) \$varcomp

wald.asreml (modelbri, ssType = "conditional", denDF="numeric")\#Test significance of fixed effects

modelbri\$coefficients\$fixed \#Coefficients of fixed effects

pin2 (modelbri, h2 V3/(V1+V3+V4)) \#First h2

pin2 (modelbri, h2 V3/(V2+V3+V5)) \#Second h2

pin2 (modelbri, $\mathrm{CE} \sim \mathrm{V} 1 /(\mathrm{V} 1+\mathrm{V} 3+\mathrm{V} 4)$ ) \#First $\mathrm{VCE} / \mathrm{VP}$

pin2 (modelbri, CE V2/(V2+V3+V5)) \#Second VCE/VP

modelbri2<-asreml (fixed=brightness_n 1 + Sex +Vane + Year

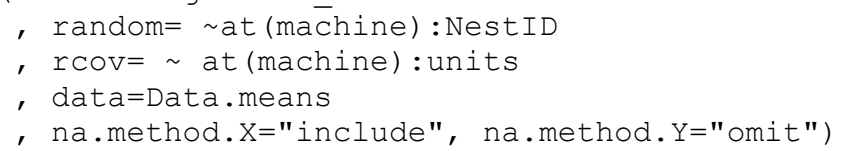

summary (modelbri2) \$varcomp

1-pchisq (2* (modelbri\$loglik-modelbri2\$loglik),1) \#Test if VA in brightness is significantly different from zero

\# II) Hue modelhue<-asreml (fixed=hue $\mathrm{n} \sim 1$ +Vane+Sex+ Year

, random $=-\sim$ ped (Ring) + at (machine) $:$ NestID

, $r \mathrm{cov}=\sim$ at (machine) : units 


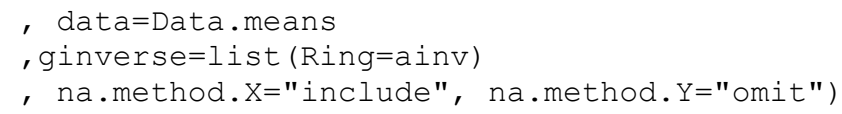

summary (modelhue) \$varcomp

wald.asreml (modelhue, ssType = "conditional", denDF="numeric")\#Test significance of fixed effects

modelhue\$coefficients\$fixed\#Coefficients of fixed effects

pin2 (modelhue, h2 V3/(V1+V3+V4)) \#First h2

pin2 (modelhue, h2 V3/(V2+V3+V5)) \#Second h2

pin2 (modelhue, CE V1/(V1+V3+V4)) \#First VCE/VP

pin2 (modelhue, CE V2/(V2+V3+V5)) \#Second VCE/VP

modelhue2<-asreml(fixed=hue_n 1 +Vane+Sex+ Year

, random= at (machine) : NestID

, rcov $=\sim$ at (machine) : units

, data=Data.means

summary (modelhue2)

, na.method.X="include", na.method.Y="omit")

1 -pchisq $(2 *$ (modelhue\$loglik-modelhue2\$loglik),1)\#Test if VA in hue is significantly different from zero

\# III) UV chroma

modelUV<-asreml (fixed=UV.chrome n 1 +Vane +Sex + Year

, random $=\sim \operatorname{ped}(\overline{\mathrm{R}}$ ing) + at (machine) : NestID

, rcov= at (machine) : units

, data=Data.means

, ginverse=list (Ring=ainv)

, na.method.X="include", na.method.Y="omit")

summary (modelUV) \$varcomp

wald.asreml (modelUV, ssType = "conditional", denDF="numeric")\#Test significance of fixed effects

modelUV\$coefficients\$fixed\#Coefficients of fixed effects

pin2 (modeluV, h2 V3/ (V1+V3+V4)) \#First h2

pin2 (modeluV, h2 V3/(V2+V3+V5)) \#Second h2

pin2 (modelUV, CE V1/(V1+V3+V4)) \#First VCE/VP

pin2 (modelUV, CE V2/(V2+V3+V5)) \#Second VCE/VP

modelUV2<-asreml (fixed=UV. chrome n 1 +Vane+Sex+ Year

, random= $\sim$ at (machine) : NestID

, rcov $=\sim$ at (machine) : units

, data=Data.means

summary (modelUV2)

, na.method.X="include", na.method.Y="omit")

1 -pchisq $(2 *$ (modelUV\$loglik-modelUV2\$loglik), 1$)$ \#Test if VA in UV chroma is significantly different from zero

\# IV) PHA

modelPHA<-asreml (fixed=PHA $1+$ Year+Sex

, random $=\sim$ ped (Ring) +NestID

, data=Data.means

, ginverse=list (Ring=ainv)

, na.method.X="include", na.method.Y="omit")

summary (modelPHA) \$varcomp

wald.asreml (modelPHA, ssType = "conditional", denDF="numeric")\#Test significance of fixed effects

modelPHA\$coefficients\$fixed\#Coefficients of fixed effects 


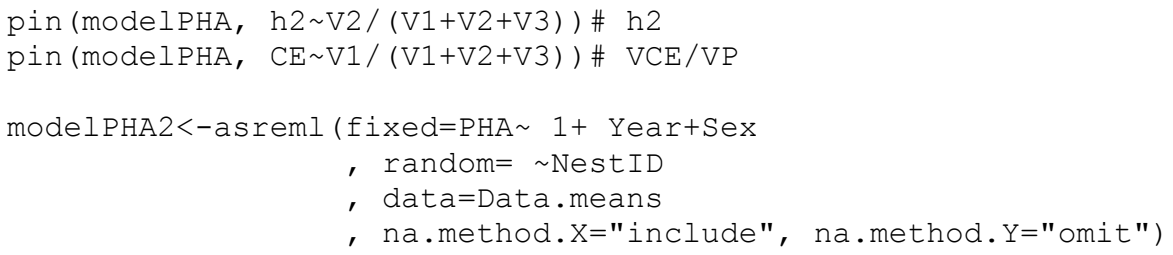

summary (modelWing) \$varcomp

wald.asreml (modelWing, ssType = "conditional", denDF="numeric")\#Test significance of fixed effects

modelWing\$coefficients\$fixed\#Coefficients of fixed effects

pin (modelWing, h2 V2/(V1+V2+V3)) \# h2

pin (modelWing, $\mathrm{CE} \sim \mathrm{V} 1 /(\mathrm{V} 1+\mathrm{V} 2+\mathrm{V} 3))$ \# $\mathrm{VCE} / \mathrm{VP}$

modelWing $2<-$ asreml (fixed=Wing 1+ Year+Sex

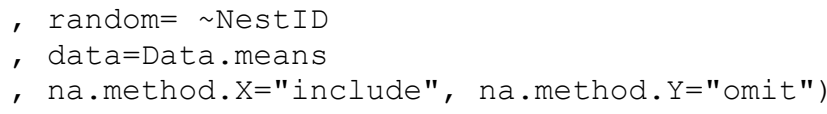

summary (modelWing2) \$varcomp

1-pchisq (2* (modelWing\$loglik-modelWing2\$loglik), 1) \#Test if VA in Wing length is significantly different from zero

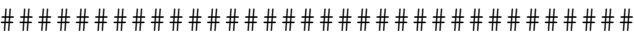

\#Multivariate models

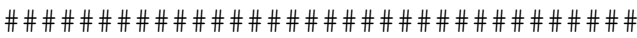

\#\#\#ultivariate model for all condition traits 


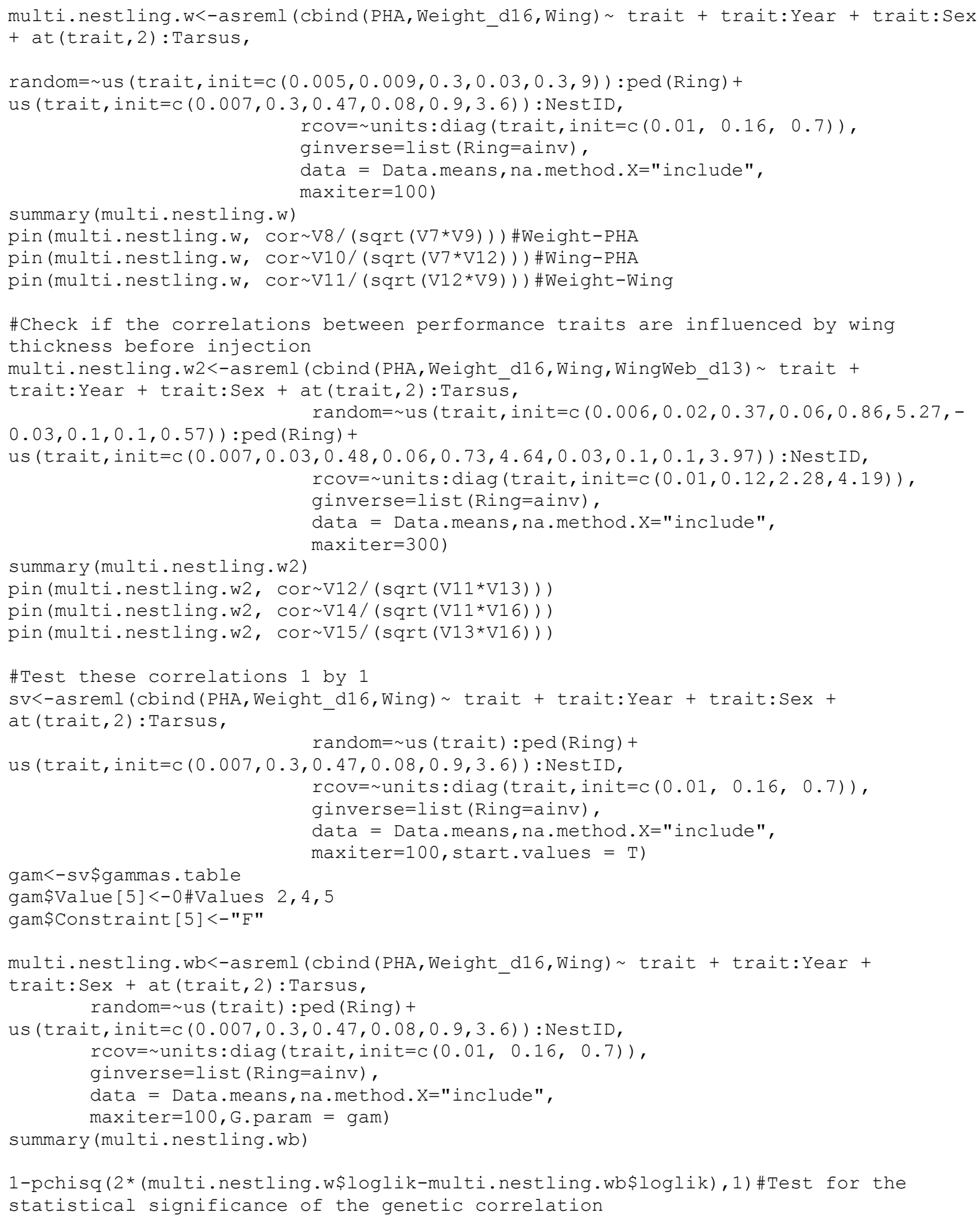

\#\#\#ultivariate model for all coloration traits

multi.nestling.c<-asreml (cbind(brightness_n, UV.chrome_n, hue_n) trait + trait:Year + trait:Sex + trait:Vane, random $=\sim$ us (trait, init $=c(0.90,-1.22 e-3,1.62 e-5,-0.25,-6 e-$ $3,13.11))$ : at (machine, init $=c(1,2)):$ NestID + us (trait, init $=c(0.24,-5 e-4,8 e-6,-0.4,-$ $4 e-3,8))$ : ped (Ring),

$3,40.5)$ ) : at (machine, init=c $(1,2))$, rcov $=\sim$ units: us (trait, init $=c(2,-1.44 e-3,3.7 e-5,-0.56,-5.8 e-$ ginverse=list (Ring=ainv), data $=$ Data.means, na.method.X="include", 


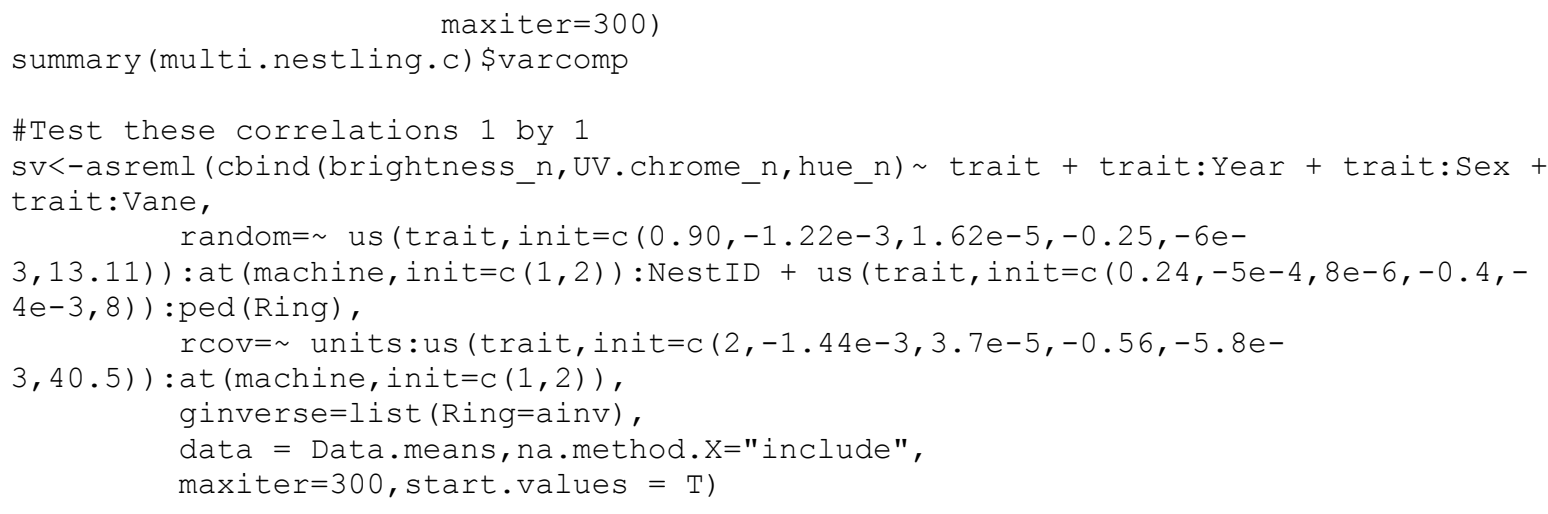

gam<-sv\$gammas.table

gam\$Value [17]<-0\#values 14,16,17

gam\$Constraint [17]<-"F"

multi.nestling.cb<-asreml(cbind(brightness_n, UV.chrome_n, hue_n) trait + trait:Year + trait:Sex + trait:Vane, random $=\sim$ us (trait, init $=c(0.90,-1.22 e-3,1.62 e-5,-0.25,-6 e-$

3,13.11)) : at (machine, init=c $(1,2)):$ NestID + us (trait) :ped (Ring), rcov $=\sim$ units: us (trait, init $=\mathrm{C}(2,-1.44 e-3,3.7 e-5,-0.56,-5.8 e-$

$3,40.5)$ ) : at (machine, init=c $(1,2)$ ), ginverse=list (Ring=ainv), data $=$ Data.means, na.method.X="include", maxiter=300, G.param=gam)

summary (multi.nestling.cb)

1-pchisq(2* (multi.nestling.c\$loglik-multi.nestling.cb\$loglik),1)\#Test for the statistical significance of the genetic correlation

\#\#\#Mltivariate model for all six traits

\#Need to specify starting values

sv<-asreml (cbind (brightness n, hue n, UV. chromen, PHA, Weight d16,Wing) trait + trait:Year + trait:Sex + at (trait, 1):Vane+ at (trait, 2):Vane+ at (trait, 3):Vane+ at (trait, 5) : Tarsus,

random $=\sim$ us (trait):ped (Ring) + us (trait):at (machine): NestID,

rcov $=\sim$ units:us (trait) : at (machine),

ginverse=list (Ring=ainv),

data $=$ Data.means, na.method.X="include",

gam<-sv\$gammas. table

maxiter $=300$, start.values $=$ TRUE)

gam $[1: 21,1: 2]$ \#pedigree

gam\$Value $[1: 21]<-c(2.77 \mathrm{E}-01$, 5.19E-06,

$-1.85 \mathrm{E}-03$

$-7.98 \mathrm{E}-01$

$4.45 \mathrm{E}+00$,

$-1.60 \mathrm{E}-04$,

$-1.63 \mathrm{E}-03$

$-1.86 \mathrm{E}-04$

$-5.69 \mathrm{E}-03,-8.29 \mathrm{E}-05$,

$5.32 \mathrm{E}-03$,

$5.31 \mathrm{E}-02$

$1.28 \mathrm{E}-01$

1. 65E-01,

$2.30 \mathrm{E}-01$

3. $44 \mathrm{E}-01$,

$-1.42 \mathrm{E}+00,-1.01 \mathrm{E}-03$

$3.04 \mathrm{E}-02$

gam $[22: 42,1: 2]$ \#Nest ID1

gam\$Value $[\mathrm{c}(22: 42)]<-\mathrm{c}(1.04 \mathrm{E}+00,-4.21 \mathrm{E}-01$ 1. $74 \mathrm{E}-05,4.19 \mathrm{E}-02$,

$9.01 \mathrm{E}-04,5.25 \mathrm{E}-02$,

$$
-9.47 \mathrm{E}-03,7.64 \mathrm{E}-05
$$

1.29E+01,

$-1.50 \mathrm{E}-03$

$-4.17 \mathrm{E}-03$

1.18E+00,

$5.96 \mathrm{E}-01,1.50 \mathrm{E}+00$,

1.12E-02,

$3.40 \mathrm{E}-01$

$3.06 \mathrm{E}-01$

$1.21 \mathrm{E}+00$

1.80E-04,

$1.41 \mathrm{E}-01$

gam $[43: 63,1: 2]$ \#Nest ID2

gam\$Value $[\mathrm{c}(43: 63)]<-\mathrm{c}(1.95 \mathrm{E}+00,-1.52 \mathrm{E}+00$, 1. $44 \mathrm{E}-04,1.35 \mathrm{E}-02$,

$-2.20 \mathrm{E}-03, \quad 1.89 \mathrm{E}-02$,

2. 51E+01,

3. 45E-03,

$-1.16 \mathrm{E}-02$

$-1.74 \mathrm{E}-02$, 
6.67E-01, $\begin{gathered}4.61 \mathrm{E}-01,1.51 \mathrm{E}+00, \quad-2.00 \mathrm{E}+00, \quad-7.99 \mathrm{E}-03, \quad 3.69 \mathrm{E}-03, \\ 4.18 \mathrm{E}+00)\end{gathered}$

gam $[65: 85,1: 2]$ \#residual1

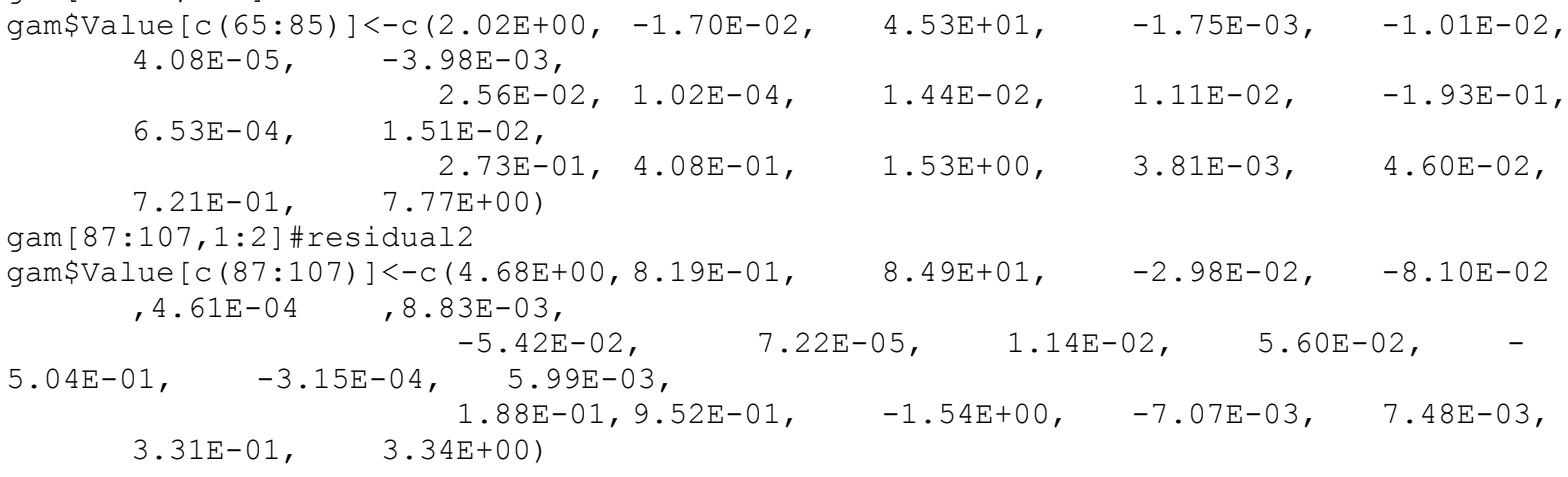

\#Run the model

multi.total.nestling<-asreml (cbind (brightness n, hue n, UV. chrome n, PHA, Weight_d16,Wing) trait + trait:Year + trait: $\overline{S e x}+\overline{a t}($ trait, 1$): \bar{V} a n e+$ at (traít, 2): Vane+ at (trait, 3):Vane+ at (trait, 5):Tarsus,

us (trait) : at (machine) : NestID random $=\sim$ us (trait) : ped (Ring) + rcov $=\sim$ units:us (trait): at (machine), ginverse=list (Ring=ainv),

R.param=gam, data $=$ Data.means, na.method.X="include", G.param=gam, maxiter=100)

summary (multi.total.nestling) \$varcomp

\#Calculate genetic correlations and their SE using the pin function

pin (multi.total.nestling,rg V44/sqrt (V43*V45)) \#hue-bri pin (multi.total.nestling,rg V46/sqrt (V43*V48)) \#UV-bri pin (multi.total.nestling,rg V47/sqrt (V45*V48)) \#UV-hue

pin (multi.total.nestling,rg V49/sqrt(V43*V52)) \#PHA-bri pin (multi.total.nestling,rg V50/sqrt (V45*V52)) \#PHA-hue pin (multi.total.nestling,rg V V1/sqrt (V48*V52)) \#PHA-UV

pin (multi.total.nestling,rg V53/sqrt(V43*V57)) \#Weight- Bri pin (multi.total.nestling,rg V54/sqrt (V45*V57)) \#Weight- Hue pin (multi.total.nestling,rg V V5/sqrt (V48*V57)) \#Weight- UV pin(multi.total.nestling,rg V56/sqrt (V57*V52)) \#Weight- PHA

pin (multi.total.nestling,rg V58/sqrt(V43*V63)) \#Wing -Bri pin (multi.total.nestling,rg V V9/sqrt (V45*V63)) \#Wing -Hue pin (multi.total.nestling,rg V60/sqrt (V48*V63)) \#Wing- UV pin (multi.total.nestling,rg V V1/sqrt(V52*V63)) \#Wing - PHA pin(multi.total.nestling,rg V62/sqrt(V57*V63)) \#Wing -Weight

\#\#\#Multivariate model on the phenotypic level

multi.pheno.nestling<-asreml (cbind(brightness_n, hue_n, UV.chrome_n, PHA, Weight d16, Wing) trait + trait:Year + trait:Sex + at(trait, 1): $\overline{\text { Vane+ }}$ at (traìt, 2): Vane+ at (trait, 3): Vane+ at (trait, 5):Tarsus, rcov= units:us(trait), data $=$ Data.means, na.method. $\mathrm{X}=$ "include", maxiter=100)

summary (multi.pheno.nestling) \$varcomp

\#Calculate phenotypic correlations and their SE using the pin function

pin (multi.pheno.nestling,rg V3/sqrt (V2*V4)) \#hue-bri pin (multi.pheno.nestling,rg V5/sqrt (V2*V7)) \#UV-bri pin (multi.pheno.nestling,rg V6/sqrt (V4*V7)) \#UV-hue 
pin (multi.pheno.nestling,rg V8/sqrt (V2*V11)) \#PHA-bri pin (multi.pheno.nestling,rg V9/sqrt (V4*V11)) \#PHA-hue pin (multi.pheno.nestling,rg V10/sqrt (V7*V11)) \#PHA-UV

pin (multi.pheno.nestling,rg V12/sqrt(V2*V16)) \#Weight- Bri pin (multi.pheno.nestling,rg V13/sqrt (V4*V16)) \#Weight- Hue pin (multi.pheno.nestling,rg V14/sqrt (V7*V16)) \#Weight- UV pin(multi.pheno.nestling,rg V15/sqrt(V11*V16)) \#Weight- PHA

pin (multi.pheno.nestling,rg V17/sqrt(V2*V22)) \#Wing -Bri pin (multi.pheno.nestling, rg V18/sqrt (V4*V22)) \#Wing -Hue pin (multi.pheno.nestling,rg V19/sqrt (V7*V22)) \#Wing- UV pin (multi.pheno.nestling,rg V V20/sqrt(V11*V22)) \#Wing - PHA pin (multi.pheno.nestling,rg V21/sqrt(V16*V22)) \#Wing -Weight

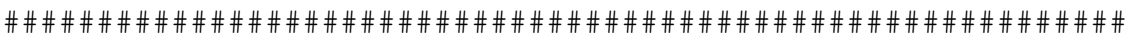

\#A different approach to calculate heritability of PHA

\#Excludes measurement error

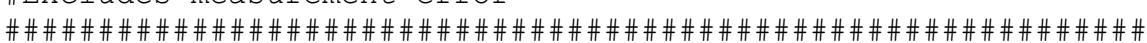

WingWebs<-read.table ("WingWebs.txt", header=T)

WingWebs \$Ring<-as. factor (WingWebs\$Ring)

WingWebs \$NestID<-as. factor (WingWebs \$NestID)

WingWebs \$Year<-as. factor (WingWebs $\$$ Year)

WingWebs $\$$ Sex<-as. factor (WingWebs $\$$ Sex)

\#Run a multivariate model with repeated measures of wing web before and after injection

multi<-asreml (cbind (WingWeb d13, WingWeb d14) trait + trait:Year + trait:Sex , random= us (träit): ped (Ring) + + us (trait): ide (Ring) +us (trait): NestID, rcov= units:diag (trait),

ginverse=list (Ring=ainv),

data $=$ WingWebs, na.method.X="include",

maxiter=1000)

summary (multi) \$varcomp

\#Calculate heritability of the difference=PHA

pin (multi, $h 2 \sim(\mathrm{V} 4+\mathrm{V} 6-2 * \mathrm{~V} 5)$ / ( ( V4 $+\mathrm{V} 6-2 * \mathrm{~V} 5)+(\mathrm{V} 1+\mathrm{V} 3-2 * \mathrm{~V} 2)+(\mathrm{V} 7+\mathrm{V} 9-2 * \mathrm{~V} 8)))$ \#heritability

pin (multi, $C E 2 \sim(V 1+V 3-2 * V 2) /((V 4+V 6-2 * V 5)+(V 1+V 3-2 * V 2)+(V 7+V 9-2 * V 8))) \# \mathrm{VCE} / \mathrm{VP}$

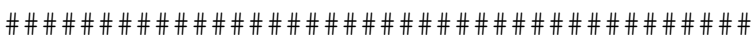

\#Estimate cross-sex genetic correlations

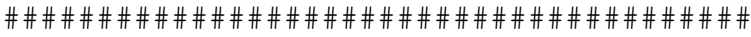

\#Create the table for analyses

Data.means. fem<-Data.means [Data.means $\$ S e x==" f "$, ]

Data.means.mal<-Data.means [Data.means $\$$ Sex $==" m "$, ]

names (Data.means.fem) [5:10]<-paste (names (Data.means.fem) [5:10], "ff", sep="") names (Data.means.mal) [5:10]<-paste (names (Data.means.mal) [5:10],"-m", sep="")

Data.means.mal\$hue $n \quad f<-N A$

Data.means.mal\$brightēness_n_f $<-N A$

Data.means.mal\$UV.chrome $\bar{n}_{-} \overline{\mathrm{f}}<-\mathrm{NA}$

Data.means. mal\$PHA $\mathrm{f}<-\mathrm{NA}$

Data.means.mal\$Weight_d16_f $<-\mathrm{NA}$

Data.means.mal\$Wing_f $\overline{<}<-\mathrm{NA}$

Data.means. fem\$hue $n m<-N A$

Data.means.fem\$brightness_n_m<-NA

Data.means.fem\$UV.chrome_ $\bar{n} \_\bar{m}<-N A$

Data.means. fem\$PHA $m<-\mathrm{NA}$

Data.means.fem\$Weight_d16_m $<-\mathrm{NA}$

Data.means.fem\$Wing_m $\overline{<}-\mathrm{NA}$

Data.means.fem<-Data.means.fem [, names (Data.means.mal) ]

names (Data.means.fem) 







\section{Text S2: $R$ code for performing structural equation modelling on the G matrix}

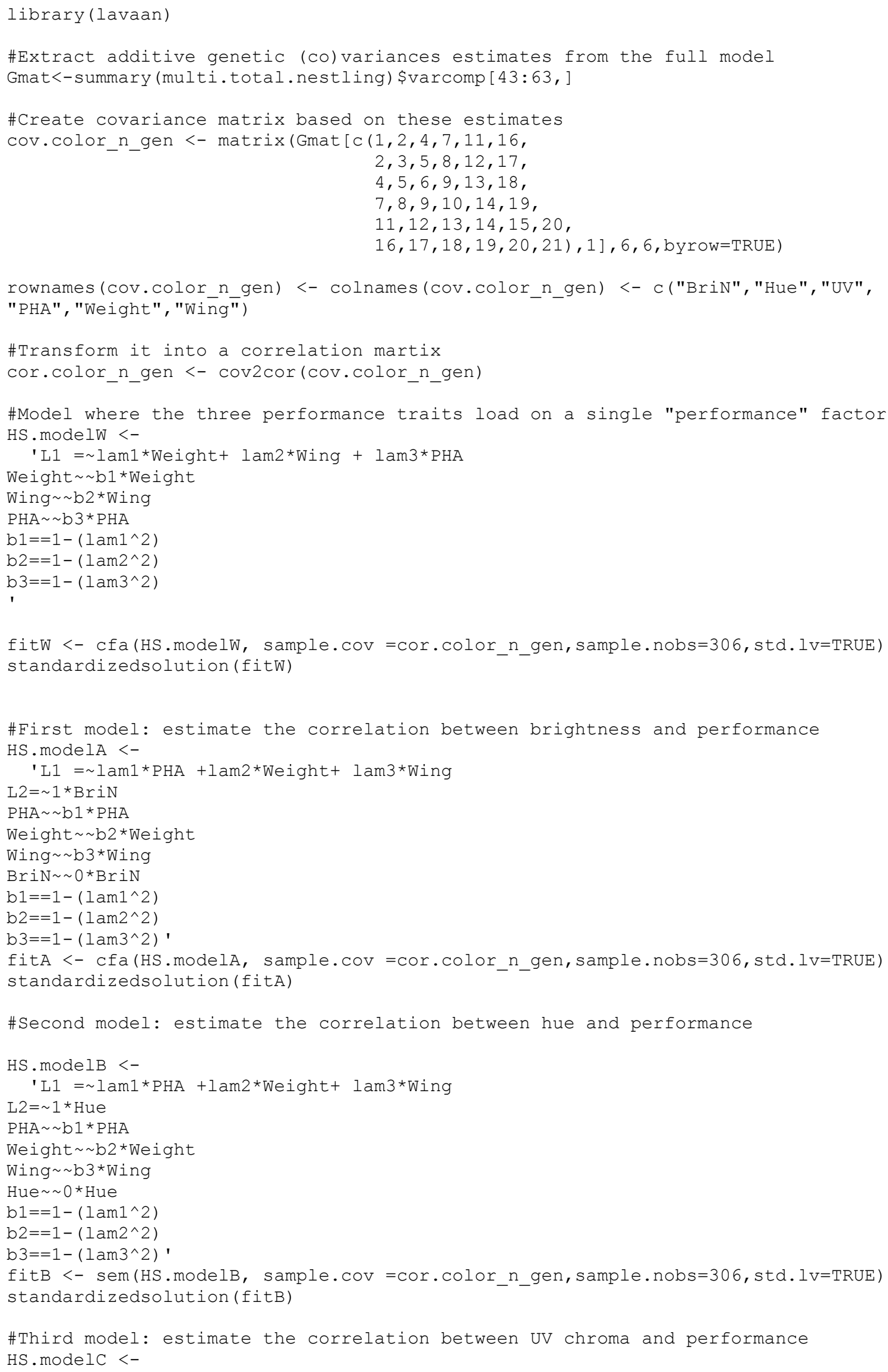




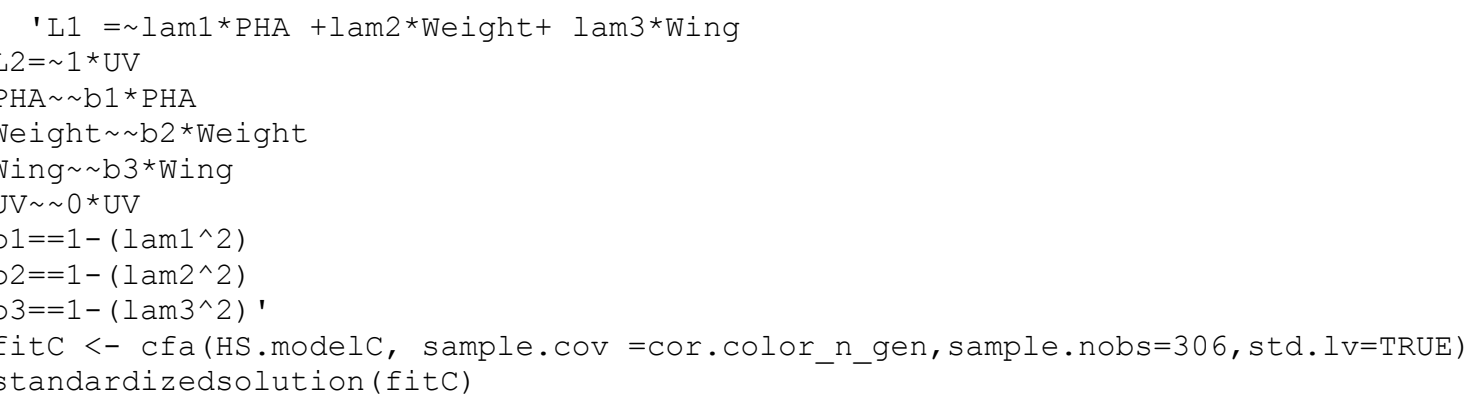




\section{Text S3: $R$ code for performing simulations}

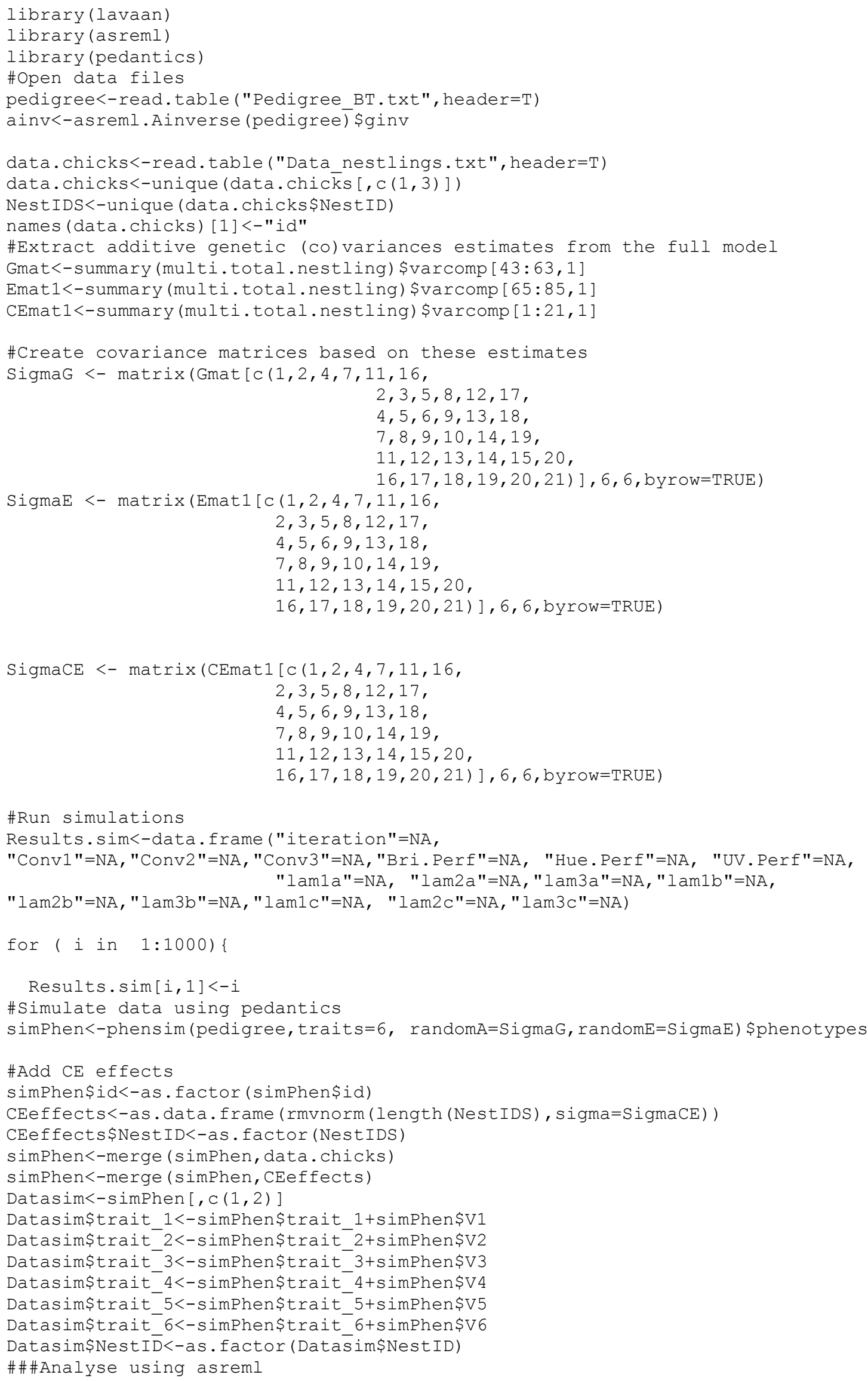

\#Run simulations

Results.sim<-data.frame ("iteration"=NA,

"Conv1"=NA, "Conv2"=NA, "Conv3"=NA, "Bri.Perf"=NA, "Hue.Perf"=NA, "UV.Perf"=NA, "lam1a"=NA, "lam2a"=NA, "lam3a"=NA, "lam1b"=NA,

"lam2b"=NA, "lam3b"=NA, "lam1c"=NA, "lam2c"=NA, "lam3c"=NA)

for $(i$ in $1: 1000)\{$

Results.sim[i, 1$]<-i$

\#Simulate data using pedantics

simPhen<-phensim(pedigree, traits=6, randomA=SigmaG, randomE=SigmaE) \$phenotypes

\#Add $\mathrm{CE}$ effects

simPhen\$id<-as.factor (simPhen\$id)

CEeffects<-as.data.frame (rmvnorm (length (NestIDS), sigma=SigmaCE))

CEeffects\$NestID<-as.factor (NestIDS)

simPhen<-merge (simPhen, data.chicks)

simPhen<-merge (simPhen, CEeffects)

Datasim<-simPhen $[, \mathrm{c}(1,2)]$

Datasim\$trait $1<-$ simPhen\$trait $1+$ simPhen $\$ V 1$

Datasim\$trait_2<-simPhen\$trait_2+simPhen\$V2

Datasim\$trait $3<-$ simPhen\$trait $3+$ simPhen\$V3

Datasim\$trait_4<-simPhen\$trait_ $4+$ simPhen\$V4

Datasim\$trait $5<-$ simPhen\$trait $5+$ simPhen\$V5

Datasim\$trait_6<-simPhen\$trait_6+simPhen\$V6

Datasim $\$$ Nest $I \bar{D}<-a s$. factor (Datasim\$NestID)

\#\#\#Analyse using asreml 
\#Run the models: need to run 3 different models because 6-trait model never converges despite starting values sv $1<-$

C (SigmaG [1,1], SigmaG[1,4],SigmaG [4,4],SigmaG[1,5],SigmaG[4,5],SigmaG[5,5], SigmaG[1, 6], $\operatorname{SigmaG}[4,6], \operatorname{SigmaG}[5,6], \operatorname{SigmaG}[6,6])$ sv2<-

C (SigmaG [2,2], SigmaG[2,4], SigmaG [4,4], SigmaG[2,5], SigmaG[4,5], SigmaG [5,5], SigmaG [2, 6], $\operatorname{SigmaG}[4,6], \operatorname{SigmaG}[5,6], \operatorname{SigmaG}[6,6])$ Sv3<-

C (SigmaG [3, 3], SigmaG [3,4],SigmaG [4,4],SigmaG [3,5], SigmaG [4,5], SigmaG [5,5], SigmaG[3, 6], $\operatorname{SigmaG}[4,6], \operatorname{SigmaG}[5,6], \operatorname{SigmaG}[6,6])$

SV $1 \mathrm{~b}<-$

C (SigmaE[1,1], SigmaE[1,4],SigmaE[4,4],SigmaE[1,5], SigmaE[4,5], SigmaE[5,5], SigmaE[1, 6], $\operatorname{SigmaE}[4,6], \operatorname{SigmaE}[5,6], \operatorname{SigmaE}[6,6])$

sv $2 \mathrm{~b}<-$

C (SigmaE [2,2], SigmaE[2,4], SigmaE[4,4], SigmaE[2,5], SigmaE[4,5], SigmaE[5,5], SigmaE[2, 6], SigmaE $[4,6], \operatorname{SigmaE}[5,6], \operatorname{SigmaE}[6,6])$

sv $3 \mathrm{~b}<-$

C (SigmaE [3, 3], SigmaE [3, 4], SigmaE [4,4], SigmaE[3,5], SigmaE[4,5], SigmaE[5,5], SigmaE[3, 6], $\operatorname{SigmaE}[4,6], \operatorname{SigmaE}[5,6], \operatorname{SigmaE}[6,6])$

Sv $1 \mathrm{C}<-$

C (SigmaCE[1,1], SigmaCE[1,4],SigmaCE[4,4],SigmaCE[1,5],SigmaCE[4,5],SigmaCE[5,5],Sig $\operatorname{maCE}[1,6], \operatorname{SigmaCE}[4,6], \operatorname{SigmaCE}[5,6], \operatorname{SigmaCE}[6,6])$

$\mathrm{sv} 2 \mathrm{C}<-$

C (SigmaCE[2,2], SigmaCE [2,4], SigmaCE[4,4], SigmaCE[2,5], SigmaCE[4,5], SigmaCE [5, 5], Sig $\operatorname{maCE}[2,6], \operatorname{SigmaCE}[4,6], \operatorname{SigmaCE}[5,6], \operatorname{SigmaCE}[6,6])$ $\mathrm{SV} 3 \mathrm{C}<-$

C (SigmaCE[3, 3], SigmaCE[3,4],SigmaCE[4,4],SigmaCE[3,5],SigmaCE[4,5], SigmaCE[5,5],Sig $\operatorname{maCE}[3,6], \operatorname{SigmaCE}[4,6], \operatorname{SigmaCE}[5,6], \operatorname{SigmaCE}[6,6])$

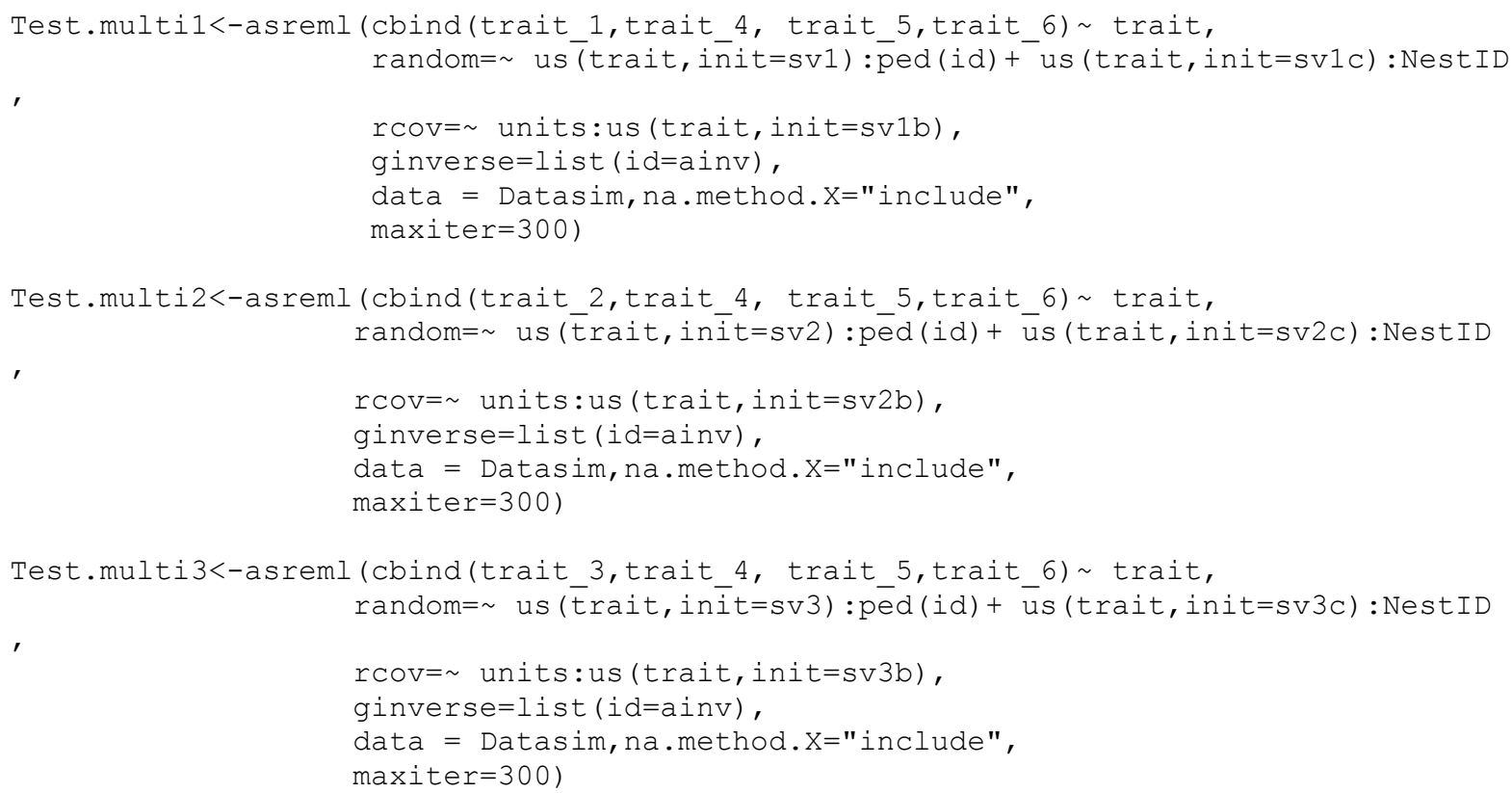

Results.sim[i,2]<-Test.multi1\$converge

Results.sim[i, 3]<-Test.multi2\$converge

Results.sim[i,4]<-Test.multi3\$converge

Gmatsim1<-summary (Test.multi1) \$varcomp $[11: 20,1]$

Gmatsim2<-summary (Test.multi2) \$varcomp $[11: 20,1]$

Gmatsim3<-summary (Test.multi3) \$varcomp $[11: 20,1]$

\#Extract covariance matrix

cov1<- matrix(Gmatsim1 $[\mathrm{c}(1,2,4,7$, 


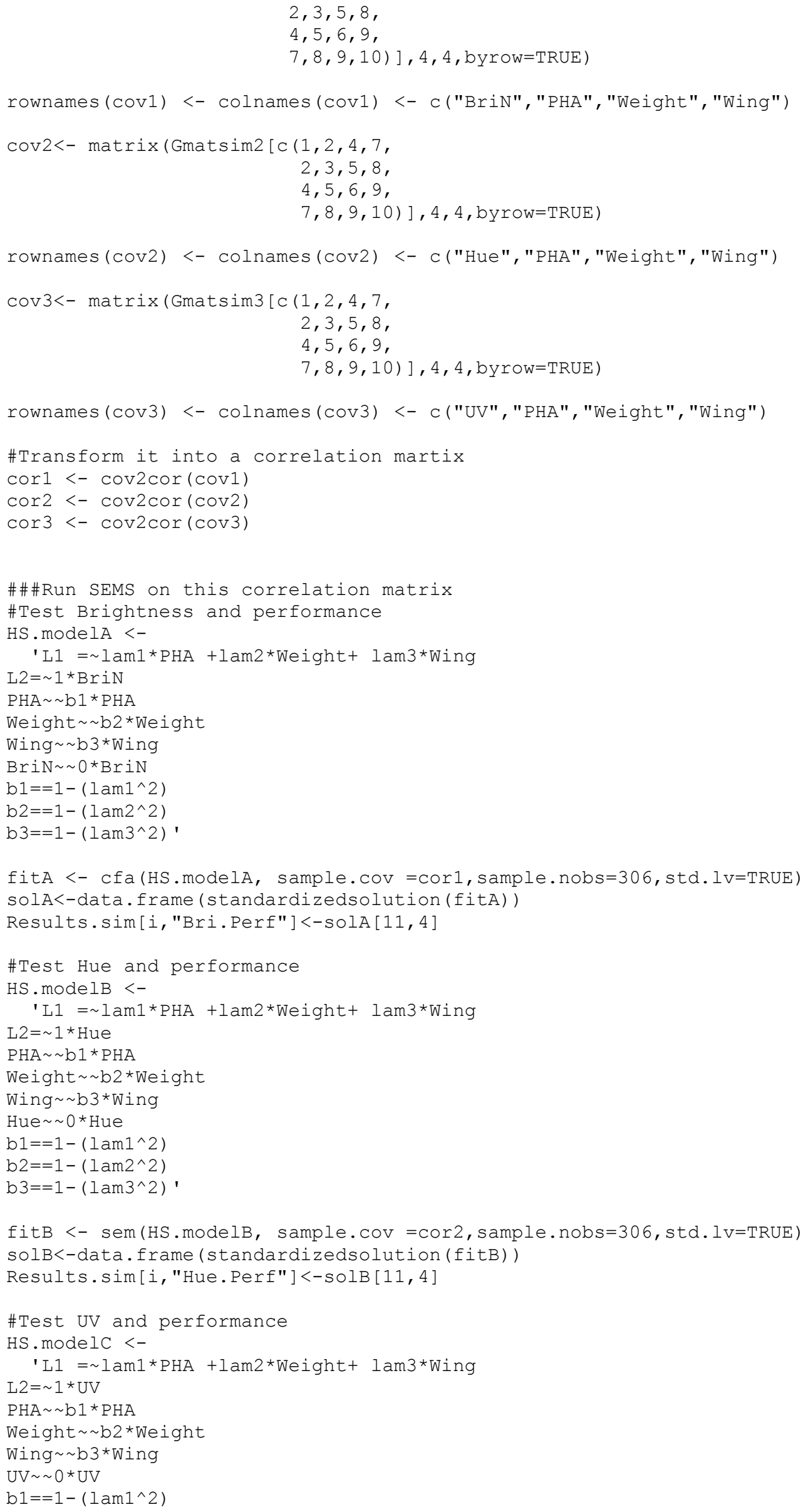




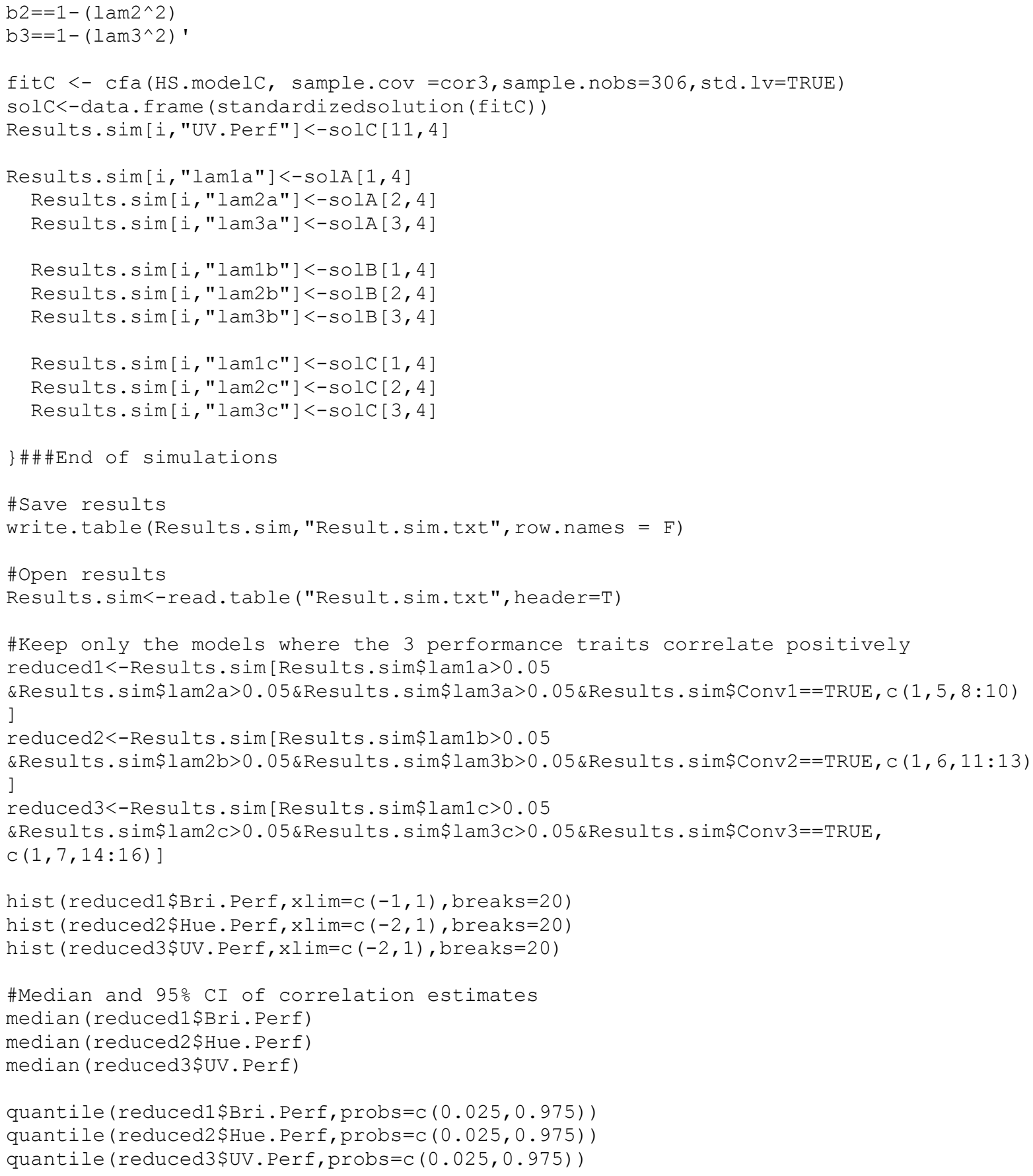


Dear Editor of Journal of Evolutionary Biology,

Thank you for your quick reply. We made the corrections that you requested in our manuscript "Tail color signals performance in blue tit nestlings" (JEB-2018-00555.R3).

Sincerely,

The author

JEB ms \# JEB-2018-00555.R2

Dear Dr. Class,

I am willing to consider acceptance of your paper for publication in JEB, provided you revise it along the lines recommended.

- Remove double brackets )), )(, (( throughout (e.g. I 244)

- state what you're reporting (line 250 - what's in the brackets? Report consistently - if that's se, then it's inconsistently reported - see line 256).

- report $95 \% \mathrm{Cl}$ as range (with a dash between, not a comma), throughout

- use space consistently in reporting results throughout (before and after numbers, $=, 95 \% \mathrm{Cl}, 95 \% \mathrm{Cl}$ ect.)

Please pay careful attention to the formatting of tables, figures and references, as well as the style used for reporting the results of statistical tests (see Instructions for Authors, http://onlinelibrary.wiley.com/journal/10.1111/\%28ISSN\%291420-

9101/homepage/ForAuthors.html)

Please make sure any in-line statistics conform to the Instructions for authors ("In-line statistical results should be presented as Test-statistics: degrees of freedom as subscript(s) to test-statistics (e.g. $\mathrm{F} 1,12=\ldots$ or $\mathrm{t} 8=\ldots$ ), followed by $\mathrm{P}$-value., e.g. $(\mathrm{F} 1,12=4.931, \mathrm{P}=0.0464)$. Statistical results in tables should be comprehensive, allowing future meta-analyses. Depending on the details of the analyses, results reported may include parameter estimates, test-statistics, degrees of freedom, significance levels and err/residual model information (e.g. error MS's and df's in ANOVA or regression models). Since exact $P$-values can be useful for meta-analyses, we recommend that these are quoted even when non-significant, e.g. t23=0.25, $\mathrm{P}=0.34$, or $\mathrm{F} 2,32=1.12, \mathrm{P}=0.55$. However, non significant tests (i.e. $P>0.05$ ) should always be interpreted as such.")

Please submit your revised paper in an editable format, within 30 days from the date of this letter, since otherwise it will be considered as a newly submitted manuscript. You can access the revision submission by clicking on the link Manuscripts with Decisions in your Author Center.

Sincerely,

Julia Schroeder 